\title{
Defining and Measuring the Mean Residence Time of Lateral Surface Transient Storage Zones in Small Streams
}

Tracie R. Jackson

Water Resources Engineering Program and College of Earth, Ocean, and Atmospheric Sciences

Oregon State University

104 CEOAS Admin. Bldg.

Corvallis, OR 97331-5503

jacksotr@engr.orst.edu

541-737-1201

Roy Haggerty

College of Earth, Ocean, and Atmospheric Sciences and Institute for Water and Watersheds

Oregon State University

104 CEOAS Admin. Bldg.

Corvallis, OR 97331-5503

haggertr@geo.oregonstate.edu

541-737-1210

Sourabh V. Apte

Department of Mechanical, Industrial, and Manufacturing Engineering

Oregon State University

204 Rogers Hall, Corvallis, OR 97331

sva@engr.orst.edu

541-737-7335

Anthony Coleman

Water Resources Science Program and College of Earth, Ocean, and Atmospheric Sciences

Oregon State University

104 CEOAS Admin. Bldg.

Corvallis, OR 97331-5503

colemana@geo.oregonstate.edu

541-737-1201

Kevin J. Drost

Department of Mechanical, Industrial, and Manufacturing Engineering

Oregon State University

204 Rogers Hall, Corvallis, OR 97331

drostk@engr.orst.edu

541-737-7335 


\begin{abstract}
Surface transient storage (STS) has functional significance in stream ecosystems because it increases solute interaction with sediments. After volume, mean residence time is the most important metric of STS, but it is unclear how this can be measured accurately or related to other timescales and field-measureable parameters. We studied mean residence time of lateral STS in small streams over Reynolds numbers $(R e)$ 5,000 — 200,000 and STS width to length (W/L) aspect ratios between $0.2-0.75$. Lateral STS have flow fields characterized by a shear layer spanning the length of the STS entrance, and one primary gyre and one or more secondary gyre(s) in the STS. The study's purpose was to define, measure, and compare residence timescales: volume to discharge ratio (Langmuir timescale); area under normalized concentration curve; and characteristic time of exponential decay, and to compare these timescales to field measureable parameters. The best estimate of STS mean residence time-primary gyre residence time-was determined to be the first characteristic time of exponential decay. An apparent mean residence time can arise, which is considerably larger than other timescales, if probes are placed within secondary gyre(s). The Langmuir timescale is the minimum mean residence time, and is linearly correlated to channel velocity and STS width. The lateral STS mean residence time can be predicted using a physically-based hydromorphic timescale derived by Uijttewaal et al. [2001] with an entrainment coefficient of $0.031 \pm 0.009$ for the $R e$ and $W / L$ studied.
\end{abstract}




\section{Introduction}

Transient storage is the temporary entrainment of stream water in recirculating flow in the stream channel (surface transient storage (STS)) or in slow flow in the hyporheic zone (hyporheic transient storage (HTS)). The lower velocities and structure of STS and HTS provide refugia for aquatic species [Lancaster and Hildrew, 1993]. STS and HTS also increase solute interaction with biogeochemically-reactive sediments by their longer residence times, which can improve water quality by removing metals [e.g., Bencala et al., 1984]; organic contaminants [e.g., Squillace et al., 2003]; radionuclides [e.g., Cerling et al., 1990]; and other pollutants through biotic (e.g., nitrification and denitrification by bacteria) and abiotic (e.g., adsorption, redox) processes.

Many hydrodynamic metrics have been developed to characterize transient storage, which is typically estimated using tracer injection techniques [Gooseff et al., 2005] because tracer concentration breakthrough curves (BTC) tails are sensitive to transient storage [Hays, 1966; Nordin and Troutman, 1980; Haggerty et al., 2000; 2002]. Common transient storage metrics include: the ratio of cross-sectional transient storage area to cross-sectional main channel area, $A_{s} / A$ [Thackston and Schnelle, 1970; Bencala and Walters, 1983]; transient storage residence time, $\alpha A_{s} / A$, where $\alpha$ is the mass exchange rate coefficient [Thackston and Schnelle, 1970]; the storage exchange flux, $\alpha A$ [Harvey et al., 1996]; the hydrological retention factor, $A_{s} / u / A$, where $u$ is the main channel advective velocity [Morrice et al., 1997]; and the total reach volume fraction occupied by transient storage, $A_{s} /\left(A_{s}+A\right)$ [Runkel, 2002]. Runkel [2002] developed a hydrodynamic metric to quantify the interaction between $u, \alpha$, and $A_{s}$, termed the median travel time fraction due to transient storage. While the fraction of median travel time due to transient storage better decouples main channel and transient storage effects on mass transport, 
no metric has been identified to decouple the properties of STS from HTS (i.e., residence times, relative storage zone areas, and exchange rates) when using current tracer methods. In addition, model parameters used to estimate transient storage are empirical in nature and, therefore, not transferrable to other streams.

Currently, advances in areas of hydrology and stream ecology are thwarted by the inability to differentiate STS from HTS [Harvey et al., 1996; Salehin et al., 2003; Ensign and Doyle, 2005]. STS and HTS have distinct influences on stream ecosystems due to differing biogeochemistry, surface area, and exchange timescales (i.e., residence time distributions (RTDs)) that depend on stream geomorphic and hydraulic properties [Valett et al., 1996; Lautz and Siegel, 2007]. For example, many studies assume that all significant exchange is hyporheic [e.g., Valett et al., 1996; Morrice et al., 1997; Haggerty et al., 2002; Battin et al., 2003]. This assumption may be inaccurate for redox-sensitive or photoactive solutes, for streams with large surficial biofilms, or for streams with a large STS component [Mulholland et al., 1997; Kasahara and Wondzell, 2003; Gooseff et al., 2005; Briggs et al., 2009; Argerich et al., 2011]. Therefore, our science needs to distinguish STS and HTS when determining the influence of transient storage on nutrient uptake functional relationships [Harvey et al., 1996; Hall et al., 2002; Salehin et al., 2003; Ensign and Doyle, 2005], so that we can determine whether specific processes are occurring in-stream, in the hyporheic zone, or both [Harvey and Wagner, 2000].

A few field-based studies have quantitatively measured STS residence times using tracers [e.g., Ensign and Doyle, 2005; Gooseff et al., 2005; Lautz and Siegel, 2006; Phanikumar et al., 2007; Stofleth et al., 2008; Briggs et al., 2009; Anderson and Phanikumar, 2011]. However, current techniques are time-consuming, subject to interference from HTS residence times, and probably do not scale reliably because the theoretical underpinnings are poor. Our goal, 
therefore, is to develop physically-based predictive STS RTDs and mean residence times for different types of STS that are applicable for a range of Reynolds Numbers $(R e)$ and STS geometries in order to separate STS from HTS.

As a first step toward this goal, we studied a specific type of natural STS-a straight open channel with a lateral cavity (Figure 1) —at twenty-two field sites located along reaches of four small, higher-gradient streams in Oregon. Other types of STS have been documented in the literature, including coarse woody debris [Ensign and Doyle, 2005], submerged aquatic canopies [Nepf, 1999], and pools, to name a few. Natural lateral STS were chosen in this study because this type of STS has been observed in many rivers and streams, including the Willamette, Santiam, and Alsea Rivers of Oregon [Jackson, unpublished data], and previous studies have referenced the occurrence of natural lateral STS in streams [e.g., O’Connor et al., 2010]. One common occurrence of lateral STS in streams is downstream of erosion-resistant features (e.g., trees, logs, boulders). Although a systematic study of different STS is yet to be done, lateral STS in some streams may produce the largest fraction of STS residence time and volume, which are the two most important metrics of transient storage [Hays, 1966; Thackston and Schnelle, 1970; Nordin and Troutman, 1980; Bencala and Walters, 1983].

A number of residence timescales have been used in studies to characterize STS mean residence times: (1) the mean hydraulic residence time (volume to discharge ratio or Langmuir timescale) [e.g., Langmuir, 1908; Hays, 1966; Kurzke et al., 2002; Kozerski et al., 2006; Weitbrecht et al., 2008]; (2) the first temporal moment normalized by the zeroth temporal moment of the residence time distribution [e.g., Aris, 1956; 1958; Nauman, 1981; Sardin et al., 1991; Patwardhan, 2001; Kurzke et al., 2002]; and (3) the characteristic time of exponential decay [e.g., Nauman, 1981; 1985; Seo and Maxwell, 1992; Buffoni et al., 1997; Bellucci et al., 
2001; Uijttewaal et al., 2001; Engelhardt et al., 2004; Kozerski et al., 2006; Hinterberger et al., 2007; Roussinova and Kresta, 2008; Weitbrecht et al., 2008; Constantinescu et al., 2009]. Mathematical definitions of these timescales are given in section 3.2. These residence timescales are not always equivalent in practice, even though they are equivalent in classical residence time theory as applied to continuous stirred tank reactors (CSTRs), which are sometimes used as a conceptual model for an STS zone [Hays, 1966]. This deviation occurs because classical CSTRs are closed systems without internal dead zones [Nauman, 1981; Buffham, 1985], but STS zones are always open systems and usually have internal dead zones. An open system has mixing across the entrance and exit boundaries, such that particles can enter and exit more than once, whereas a closed system does not have mixing across the entrance and exit boundaries, such that particles can enter and exit only once. All three of the residence timescales are equivalent for closed systems; however, this is not true for open systems. A lateral STS zone is an open system because the entrance and exit are intermixed within the shear layer that forms along the STS entrance and allow for mixing and re-entrance to the STS (Figure 1). Internal dead zones further complicate the definition and measurement of mean residence time. As all three of the residence timescales have been defined as a mean residence time, uncertainty exists as to which is the appropriate STS mean residence time. In addition, research to date has neither developed a standardized method to accurately measure STS mean residence times in the field nor established how the mean residence time is related to other field-measureable parameters.

The purpose of this paper is, therefore, to define the appropriate mean residence time of lateral STS in small streams for a range of Re and STS geometries and to relate the STS mean residence time to physically-based stream parameters. Lateral STS field sites studied have flow fields characterized by a shear layer that spans the length of the STS entrance, and a large 
primary gyre and one or more secondary gyres in the STS (Figure 1). Twenty-two field sites with natural lateral STS were selected in this study and had main channel Re that ranged from 5,000 to 200,000 (based on main channel wetted perimeter) or from 40,000 to 1,000,000 (based on STS width) (Table 1). The lateral STS aspect ratio $(W / L)$, where $W$ is the cavity width (normal to flow) and $L$ is the cavity length at the main channel-STS interface (parallel to flow) (Figure 1a), ranged from 0.2 to 0.75 (Table 1). The objectives of this paper are to: (1) develop a theoretical mean residence time for lateral STS based on the steady flow field results of a computational fluid dynamics (CFD) model and on the results of laboratory and numerical studies in the range of $R e$ and W/L studied; (2) quantitatively relate residence timescales to the theoretical mean residence time and determine the appropriate metric for the STS mean residence time; (3) quantitatively relate residence timescales to an apparent (false) measured mean residence time that arises when electrical conductivity probes are improperly placed in poorly-mixed regions of the STS (i.e., secondary gyres); (4) relate residence timescales to physically measureable parameters in the field to develop predictive relationships; and (5) determine the physical processes controlling the different residence timescales and the occurrence of one- or twoexponential RTDs using gyre dynamics.

This paper introduces a new approach to study natural lateral STS that integrates fluid dynamics and classical residence time theory. Fluid dynamics will be incorporated into the understanding of physical processes controlling the STS mean residence time, apparent measured mean residence time, and the occurrence of one- and two-exponential RTDs. Fundamental fluid dynamics is included because fluid interaction with channel bed and banks results in flow separation, induced pressure gradients with mean and fluctuating components, velocity shear in vertical and transverse directions, and recirculation, all of which form three-dimensional vortical 
structures with differing length and timescales [Boano et al., 2001; Keylock et al., 2005], which altogether influences STS residence timescales and RTDs. The basis for incorporating fluid dynamics to study lateral STS is not to include the complexities of the flow field in the computation of mean residence time, but to provide a better understanding of the mechanisms that entrain solute.

\section{Conceptual Framework}

Before presenting the methods and results of a field study (sections 3 and following), we first provide a conceptual model for flow and transport in lateral STS zones. First, we describe the typical flow features associated with lateral STS based on their resemblance to engineered (geometrically ideal) lateral cavities in open channel flows. Second, we illustrate a typical flow

field for lateral STS using a 3-D Reynolds-Averaged Navier-Stokes (RANS) computational fluid dynamics (CFD) model generated from detailed field data at a single field site. Third, using classical and contemporary residence time theory, we highlight key observations about the STS that are relevant for solute transport in streams. Fourth, based on these observations, we develop a simple box model of solute transport in STS that will provide a basis for comparing residence timescales previously defined in the literature.

\subsection{Flow Field of Lateral STS}

Lateral STS is analogous to flow past an open lateral rectangular cavity, which has been well-studied using both laboratory flumes and numerical models for the range of $R e$ and $W / L$ measured in this study [e.g., Kimura and Hosada, 1997; Muto et al., 2000; Uijttewaal et al., 2001; 2005; McCoy et al., 2006; 2007; 2008; Weitbrecht et al., 2008; Constantinescu et al., 2009]. Flume studies of incompressible, turbulent flow past ideal, rectangular cavities at high $R e$ $(>5,000)$ and $0.2 \leq W / L \leq 0.75$ show that a free-shear layer forms along the entire cavity 
entrance and generates a recirculation region in the cavity (Figure 1). The shear layer forms by flow separation at the leading edge of the cavity due to large differences in momentum and velocity between the main channel and cavity [Constantinescu et al., 2011]. Vortices in the shear layer convect downstream from the leading edge and impinge on the trailing edge, causing pressure fluctuations and the unsteady transport of vorticity into the downstream region of the cavity [Chang et al., 2006; Lin and Rockwell, 2001]. The vorticity becomes entrained and recirculates within the cavity [Chang et al., 2006; Lin and Rockwell, 2001], typically producing either: (a) one large primary gyre that inhabits the entire cavity; or (b) two or more gyres in the cavity: a primary gyre with velocity fluctuations in the downstream region and one or more counter-rotating secondary gyres [Muto et al., 2000]. The production of more than one gyre is dependent on the $W / L$ aspect ratio of the cavity. These same complex flow features are also associated with lid-driven cavity flows [Koseff et al., 1982; 1984a; 1984b; 1984c; Chiang et al., 1997; 1998; Guermond et al., 2002]; however, open lateral cavity flows have the additional complexity of mass and momentum exchange across the channel-cavity interface.

\subsection{RANS CFD Model}

The 3-D RANS CFD model was generated from detailed field data collected at site 1P, which is located along a straight riffle reach of Oak Creek in the Oregon State University McDonald-Dunn Research Forest near Corvallis, Oregon. This site was selected because the main channel $\operatorname{Re}(\sim 32,000$ based on wetted perimeter) and STS $W / L$ aspect ratio $(\sim 0.32)$ are typical of STS sites studied (Table 1). Appendix A describes the field data collection and development of the CFD model. Key results of the model are presented below.

The mean flow field results from the RANS CFD model show that typical lateral STS are comprised of a large primary gyre and a number of smaller, counter-rotating secondary gyres 
(Figure 1b). The primary gyre extends across the entire length of the STS entrance and exchanges mass and momentum from the shear layer to the secondary gyres. One counterrotating secondary gyre forms in the upstream corner due to the aspect ratio and a number of smaller gyres form along the wetted perimeter of the STS due to the irregular shaped geometry.

The flow features within a lateral STS can change significantly based on $R e, W / L$, and $W / D$, where $D$ is STS depth. Considerable experimental and numerical work has been done on driven cavity flows with varying geometric parameters and $R e$, showing various recirculation patterns over a much wider range of Re [Koseff et al., 1982; 1984a; 1984b; 1984c; Chiang et al., 1997; 1998; Guermond et al., 2002; Cheng and Hung, 2006; Lawson and Barakos, 2011]. If the length of the dead zone is very large, the shear layer may not span the entire length, eliminating primary gyres [Lawson and Barakos, 2011]. Likewise, if $W / L$ is increased considerably, multiple gyres may be stacked on each other [W/L >> 1.5; Weitbrecht and Jirka, 2001]. However, the narrow range of $W / L$ ratios and $R e$ studied in this work consistently provided the same flow features. Similar flow features also were observed for this range of $R e$ and $W / L$ in a series of lateral cavities (or groynes) with idealized geometries by Wallast et al. [1999], Weitbrecht and Jirka [2001], Uijttewaal et al. [2001; 2005], Kurzke et al. [2002], McCoy et al. [2006], Chang et al. [2007], Hinterberger et al. [2007], Weitbrecht et al. [2008], Constantinescu et al. [2009], and Ozalp et al. [2010], and RANS simulations by Kimura and Hosada [1997] and Drost et al. [2012]. We conclude that for field STS in the Re and W/L studied (See Table 1), a streamwise anisotropic primary gyre forms along the STS entrance and transfers mass and momentum from the shear layer to the secondary gyre(s), and that the flow structure (in the mean) does not significantly change.

\subsection{STS effects on RTD in Main Channel}


The choice of appropriate mean residence time depends on the use of that mean residence time. STS residence times are important because of how they modify solute transport in the main channel, and so understanding transport in the main channel is the use for measurements and calculations of STS mean residence time. STS modifies the RTD of solutes in the main channel and its effects have been studied extensively in the context of transport with mobile-immobile domain mass transfer, which is mathematically similar. There is a deep literature on this, and important reviews from the chemical engineering and groundwater perspectives are provided by Villermaux [1974; 1981], Nauman [1981; 2008], Sardin et al. [1991]; Cunningham and Roberts [1998]; and Luo et al. [2008]. We mention the key results relevant to this study and refer the reader back to these references for more detail.

First, the most important effects of STS on the RTD in the main channel are determined by the mean residence time in the STS and by $A_{s} / A$ (relative volume of STS to channel per unit channel length); where $A_{s}$ is the STS cross-sectional area and $A$ is the cross-sectional area of the channel. This fact comes from the properties of mass transfer that (1) the area under the main channel breakthrough curve $\left(0^{\text {th }}\right.$ moment) is not influenced by STS; (2) the main channel mean arrival time $\left(1^{\text {st }}\right.$ moment normalized by $0^{\text {th }}$ moment) is only a function of $A_{s} / A$; and (3) the spread of the channel residence time ( $2^{\text {nd }}$ central moment) is only a function of the STS mean residence time and $A_{s} / A$ (see references cited above). Reactive solutes (e.g., nutrients) are influenced by the entire STS RTD, but $A_{s} / A$ and the mean residence time are still the most important characteristics of the RTD (see Sardin et al. [1991] and Argerich et al. [2011], among others).

Second, for mass transfer across a series of gyres (mass transfer in series), the STS mean residence time should be determined in the first gyre that is not part of advection in the channel (Sardin et al., 1991). The shear layer has a downstream advection rate and so it is part of the 
channel for purposes of calculating temporal moments. The first transient storage zone is the primary gyre (see Figure 1b), which transfers mass into secondary gyre(s). The mean residence time, therefore, will be determined by the primary gyre. The volume of the secondary gyre(s) affects the mean residence time of the primary gyre and the second moment in the channel. The residence time of secondary gyres affects only the third and higher moments in the channel and does modify the shape of the tail of the breakthrough curve in the channel. Furthermore, the secondary gyres may be influential on a reactive solute if the secondary gyres have residence times similar to the reaction timescale. To emphasize: the secondary gyres' residence times have no influence on the channel's $0^{\text {th }}, 1^{\text {st }}$, or $2^{\text {nd }}$ temporal moments for a conservative tracer.

\subsection{Box model of Lateral STS}

The box model consists of the main or primary gyre (1), and one or more secondary gyres, denoted as $i=1,2, \ldots, \mathrm{N}$, that interact with the primary gyre (2) (Figure 2). The box model divides the STS into multiple CSTRs and assumes: (1) that each of the regions is individually well mixed; (2) that flow is steady and incompressible; and (3) that there are no sources and sinks other than those specified. The mass balance is expressed with first-order equations, where mass exchange is linearly proportional to the mean concentration difference between any two regions. The mass balance equations are:

$$
\begin{aligned}
& \frac{d C_{p}}{d t}=\frac{Q_{p m}}{V_{p}}\left(C_{m}-C_{p}\right)+\frac{Q_{i n j}}{V_{p}} C_{i n j}+\sum_{i=1}^{N} \frac{Q_{p s_{i}}}{V_{p}}\left(C_{s_{i}}-C_{p}\right) \\
& \sum_{i=1}^{N} \frac{d C_{s_{i}}}{d t}=\sum_{i=1}^{N} \frac{Q_{p s_{i}}}{V_{s_{i}}}\left(C_{p}-C_{s_{i}}\right)
\end{aligned}
$$

where $C$ is concentration; $Q$ is discharge in or out; and $V$ is volume. All discharges except $Q_{i n j}$ are defined as $1 / 2$ the sum of the absolute value of discharges in and out. The subscripts on $C$ and $V$ indicate as follows: $m$ is the main channel; $p$ is the primary gyre; $s$ is a secondary gyre that 
interacts only with the primary gyre; and inj is injection from an external source (e.g., a pump). The subscripts on $Q$ indicate as follows: $p m$ is flow between the main channel and primary gyre; $p s$ is flow between the primary gyre and a secondary gyre; and inj is the injection rate. (See notation section for definition and units of all variables). Note that the flow is steady, meaning that the volume flux entering the STS is balanced by the volume flux leaving the STS through the shear layer, and that the volume flux entering the primary gyre is balanced by the volume flux leaving the primary gyre to secondary gyres and the shear layer. Longitudinal advection in the shear layer is not included in the mass balance because the longitudinal transport velocity is much larger than the transverse velocity (by an order of magnitude), resulting in a much smaller residence timescale for the longitudinal velocity compared to the transverse velocity. The residence time associated with the transverse velocity in and out of the shear layer is small compared to the residence time in the STS and, because the residence time associated with the longitudinal velocity is much smaller, the shear layer transport timescales can be neglected.

We define the average concentration in the STS zone as:

$$
C_{S T S}=\frac{V_{p} C_{p}+\sum_{i=1}^{N} V_{s_{i}} C_{s_{i}}}{V_{\text {STS }}},
$$

where $V_{S T S}=V_{p}+\sum_{i=1}^{N} V_{s_{i}}$. In general, $C_{S T S} \neq C_{p}$. The following variables are known: $Q_{i n j}, C_{i n j}$, $C_{S T S}$, and $Q_{p m}$ (which is equivalent to the entrainment discharge, or volumetric flow rate entering or leaving the storage zone). Two useful results with (1-3) can be obtained from steady state and moment solutions, which are presented below. 
We calculate the STS mean residence time by Laplace transformation. Setting $Q_{i n j}=0$, $C_{m}=0$, and all initial concentrations in the STS to 1 (i.e., after injection), where $C_{p}(t=0)=C_{s_{i}}(t=0)=1$, we find the solution of (1-2) in the Laplace domain. The full solution is cumbersome, but we are only interested in the solution in the limit as the Laplace variable goes to zero (i.e., infinite time), and in the temporal moments, which are calculated by Aris' method of moments [Aris, 1958]. Using Aris [1958], the STS mean residence time can be calculated from the concentration in the primary gyre, $C_{p}$ :

$$
\tau_{\text {SIS }}=\tau_{L}
$$

where $\tau_{L}$ is the primary gyre mean residence time, $\tau_{L}=V_{S T S} / Q_{p m}$, which is also the mean hydraulic residence time originally derived by Langmuir [1908]. We refer to $\tau_{L}$ as the Langmuir timescale. If we (incorrectly or inadvertently) base the measurement of mean residence time on the average concentration throughout the whole STS, $C_{S T S}$, in (3), the resulting timescale will be

$$
\tau_{a p}=\tau_{L}+\sum_{i=1}^{N} \beta_{s_{i}} \tau_{s_{i}}=\tau_{S T S}+\sum_{i=1}^{N} \beta_{s_{i}} \tau_{s_{i}}
$$

where $\tau_{a p}$ is the measured apparent mean residence time; $\tau_{s_{i}}$ is the mean residence time for each secondary gyre, $i$, that exchanges with the primary gyre, $\tau_{s_{i}}=V_{s_{i}} / Q_{p s_{i}}$; and $\beta_{s_{i}}$ is the relative volume of the STS occupied by each secondary gyre, $i, \quad \beta_{s_{i}}=V_{s_{i}} / V_{S T S}$.

\section{Methods: Field Data Collection and Computation of Residence Timescales}

\subsection{Field Data Collection}

Twenty-two field sites were selected along riffles in small streams near Corvallis, Oregon (Oak and Soap Creeks), in several small streams in the HJ Andrews Experimental Forest of Oregon, and in the Middle Fork John Day River, Oregon. Determination of whether a lateral 
indentation along the main channel was a lateral STS was based on the following criteria: (1) presence of a shear layer adjacent to the STS entrance using a visual (rhodamine WT) dye; and (2) entrance of dye into the STS and observed formation of at least one region of recirculation inside (Figure 3a). The minimum width measured among the field sites was $0.5 \mathrm{~m}$.

At each site, two to three constant-rate $\mathrm{NaCl}$ injections (at $0.06 \mathrm{~L} / \mathrm{s}$ ) were done using a pump-driven distribution system to obtain concentration breakthrough curves and RTDs. The pump-driven distribution system was comprised of twelve pressure-compensating emitters mounted to a plexiglass platform (Figure 3b-c). The platform was centered about $0.5 \mathrm{~m}$ above the STS center and the pump-driven salt injections were used to raise background concentrations to steady state. Seven to nine electrical conductivity (EC) probes were uniformly spaced (by visual inspection) on the streambed within the STS and shear layer to simultaneously collect specific conductivity at 10-s intervals [Campbell Scientific, Inc., Logan, Utah, USA]. Background concentrations were raised by 50 to $100 \mu \mathrm{S} / \mathrm{cm}$, and the steady state concentration versus time curves were used to obtain RTDs and to compute mean residence times.

Detailed morphological and velocity measurements were collected at field sites. STS width and depth were measured along 5 - 10 transects normal to flow and shear layer depths were measured parallel to flow with a wading rod and measuring tape at 5-cm increments. Channel velocity was measured at $60 \%$ depth upstream of the STS zone using a wading rod, tape, and Flo-Mate 2000 portable flowmeter [Marsh-McBirney, 1990]. Velocity data was used in the comparison of residence timescales to field-measureable parameters.

\subsection{Equations for RTD and Mean Residence Times and Methods for Computation}

Field data show that natural lateral STS typically can be characterized by either oneexponential or two-exponential RTDs. Methods are described for the computation of each 
timescale based on whether the RTD is a one-exponential or two-exponential (Figure 4). The distinction between a one- or two-exponential RTD was based on an abrupt change in slope in the concentration BTC (see Figure 4, noting that the shaded diagrams are overlain on RTDs taken from Site 7S (one-exponential RTD; Soap Creek) and Site 1P (two-exponential RTD; Oak Creek)).

Transient storage residence time theory often uses the continuous stirred tank reactor (CSTR) as a conceptual model for an STS zone, such as a pool between riffles [Hays, 1966]. From this theory, the RTD for transient storage is a probability density function (pdf) of age distribution of water molecules exiting the storage zone for the final time, given that the time of initial entrainment was $t_{i}=0$ [Buffoni et al., 1997; Botter et al., 2011]. The RTD pdf derived by Danckwerts [1953], $F\left(t_{r}\right)$, is the fraction of particles leaving the storage zone since the time of entrainment at $t_{i}=0$ between the residence time, $t_{r}$, and $t_{r}+d t_{r}$ :

$$
\int_{0}^{\infty} F\left(t_{r}\right) d t=1
$$

where $t_{r}=t-t_{i}$ and $t$ is the current time given by $t>t_{i}$ [Botter et al., 2011]. The mean residence time is the arithmetic mean of $F\left(t_{r}\right)$ [Botter et al., 2011].

The mean residence time for a CSTR [Langmuir, 1908] with no internal stagnation zones (i.e., well-mixed) [Nauman, 1981] and negligible dispersion across the inlet and outlet is

$$
\tau_{L}=\frac{V_{S T S}}{Q_{p m}}
$$

where $V_{\text {STS }}$ is the STS volume; and $Q_{p m}$ is the entrainment discharge. For all field sites, the Langmuir timescale (7), or mean hydraulic residence time, was computed using physically-based 
properties of the STS and the mass balance equation, $Q_{i n j} C_{i n j}=Q_{p m} C_{S T S}$, where $Q_{i n j}=0.06 \mathrm{~L} / \mathrm{s}$ and $Q_{i n j}<<Q_{p m}$.

A more general mean of the RTD can be obtained with temporal moments, e.g., Aris [1956; 1958]. The mean of the RTD is the first moment of the pdf. Using a conservative tracer that uniformly fills the storage zone, the first moment also is the area under the concentration curve from the end of the injection at $t=0$ normalized by the average concentration at $t=0$ [Nauman, 1981]. I.e., for a well-mixed CSTR:

$$
I_{0}^{\infty}=\int_{0}^{\infty} t_{r} F\left(t_{r}\right) d t_{r}=\int_{0}^{\infty} \frac{C(t)}{C(t=0)} d t,
$$

where $C$ is the concentration in the STS after a long injection; and $I_{0}^{\infty}$ is the normalized residence time. For practical reasons, $C(t=0)$ is the average concentration over some period of time prior to the end of injection at $t=0$. Note that $I$ indicates integral and the subscript and superscript are the lower and upper integration bounds, respectively. This notation is used because integration over different areas of the concentration curve yields different timescales that have different physical meanings (i.e., mean or apparent mean residence time) depending on whether the RTD is a one-exponential or a two-exponential. For a one-exponential RTD, the STS mean residence time, $\tau_{\text {STS }}$, was computed as the area beneath the normalized concentration curve for $0 \leq t<\infty$, denoted $I_{0}^{\infty}$. A two-exponential RTD has two timescales (Figure 4): a mean and an apparent mean residence time. The STS mean residence time, $\tau_{\text {STS }}$, was computed as the area beneath the normalized concentration curve for $0 \leq t \leq T_{2}$, denoted $I_{0}^{T_{2}}$, where $T_{2}$ represents the time where the change in slope occurs at the end of the first exponential decay and beginning of the second exponential decay. A two-exponential RTD has an apparent STS mean residence 
time, $\tau_{a p}$, unlike the one-exponential RTD, computed as the area beneath the normalized concentration curve for $0 \leq t<\infty$, denoted $I_{0}^{\infty}$.

The RTD for an ideal (well-mixed) CSTR is:

$$
F(t)=\frac{1}{\tau} \mathrm{e} x+t /(\tau)
$$

where $\tau$ is the characteristic timescale computed as the inverse slope of the exponential decay function and will be defined as either $\tau_{1}$ or $\tau_{2}$ depending on the type of RTD and the exponential decay slope. A one-exponential RTD only has one characteristic timescale, denoted $\tau_{1}$, computed as the inverse slope of the exponential decay function (i.e., concentration curve). A two-exponential RTD has two characteristic timescales (Figure 4) because the RTD has two exponential decay functions. Exponential decay begins at $T_{1}$, which is the time for initiation of the first exponential decay, and changes slope at $T_{2}$, which is the time for initiation of the second exponential decay. Note that $T_{1}$ does not always coincide with the time at the end of injection (i.e., turning off the pump at $t=0$ ) because, at some field sites, the RTDs had an initial plateau concentration due to the time lag between turning off the pump and the initial release of tracer from the primary gyre into the main channel measured by the first EC probe. The early time timescale, denoted $\tau_{1}$, was estimated from the inverse slope of the first exponential decay from $T_{1} \leq t<T_{2}$. The second timescale, $\tau_{2}$, was estimated from the inverse slope of the second exponential decay from $T_{2} \leq t<\infty$ (Figure 4).

Uijttewaal et al. [2001] developed an expression to predict the mean residence time from the dead zone model derived by Hays [1966] by incorporating the entrainment hypothesis of Valentine and Wood [1977]. In this hypothesis, $E=k U$, where $E$ is the exchange velocity 
entering or leaving the STS (Figure 1a); $U$ is the mean main channel velocity; and $k$ is a dimensionless entrainment coefficient for linear, first order mass exchange:

$$
\tau_{S T S}=\frac{W d_{S T S}}{k U d_{E}},
$$

where $d_{E}$ is the depth at the main channel-STS interface; $W$ is the width of the STS normal to flow; and $d_{\text {STS }}$ is the mean STS water depth. The mean residence time can be predicted from (10) using field-measureable parameters if the entrainment coefficient, $k$, is known; however, to date, a precise estimate of $k$ has not been found. Laboratory studies of open channel flow past rectangular cavities suggest that $k$ ranges between values of 0.01 to 0.04 [Valentine and Wood, 1977; Seo and Maxwell, 1992; Wallast et al., 1999; Uijttewaal et al., 2001; Kurzke et al., 2002; Weitbrecht and Jirka, 2001; McCoy et al., 2006; Hinterberger et al., 2007; Chang et al., 2007; Weitbrecht et al., 2008; Constantinescu et al., 2009]; see Table 2. The predictive relationship in (10) will be used as a basis for comparing mean residence timescales to stream hydromorphic parameters.

\section{Results}

Note that all relationships reported in the results have fits that are statistically significant at the $p<0.001$ level.

\subsection{Determination of 1- or 2-exponential RTDs from Experiments at STS Field Sites}

The distinction of whether a lateral STS was characterized by a one- or two-exponential RTD was based on RTDs of individual EC sensors placed within the STS during NaCl injection experiments. As an example, consider the concentration BTCs for individual EC probes during 3 different $\mathrm{NaCl}$ injections (with increasing initial concentration injections from experiment 1 to 3) at Site 2P (Oak Creek, Oregon) shown in Figure 5a. The location of each EC probe is shown in the schematic in Figure 3c, where all EC probes all located in the primary gyre region except 
probe 5 (EC5), which is located in a secondary gyre. The result of placing EC5 in a poorlymixed region (secondary gyre) is a time-lag for this BTC to reach a steady state concentration compared to the other BTCs. Oscillations in the steady-state concentrations were due to the unsteady nature of gyres in the vicinity of probes. When comparing probe locations in Figure 3c to BTCs in Figure 5a, the steady state plateau concentration increases from probes EC2 to EC8 (ignoring EC 5) due to lower concentration stream water circulating from the downstream region to the upstream region of the STS. Highest $\mathrm{NaCl}$ concentrations occurred near the center of the primary gyre due to the slower-moving velocities. $\tau_{1}$ was computed for each EC probe (Figure 5b), which each have a one-exponential RTD. All probes located in the primary gyre have consistent residence timescales, whereas the probe in the secondary gyre has a significantly larger residence timescale. The significantly differing residence timescales in two different regions of the STS resulted in a two-exponential RTD for the normalized mean concentration BTCs for each experiment (Figure 5c). The placement of EC probes can significantly influence the mean residence timescale and type of RTD obtained. All sensors located in poorly-mixed regions are removed during data analysis; however, two-exponential RTDs can still arise if EC sensors in the primary gyre are located near secondary gyres and are influenced by secondary gyre exchange.

For each normalized mean BTC, the early time decay slope has less variability between experiments than the late-time decay slope (Figure 5c). The late-time variability is attributed to the relatively short time duration between experiments ( $25 \mathrm{~min}$ ), which results in more $\mathrm{NaCl}$ in poorly-mixed regions (secondary gyres) for experiments 2 and 3 initially than in experiment 1. The higher initial concentration in secondary gyres for later experiments results in more solute exchange with the primary gyre, and changes the late-time tailing behavior of the RTD. 
Therefore, when using BTCs from multiple experiments to obtain residence timescales, results from the first experiment are used for comparison.

\subsection{Comparison of Residence Timescales}

\subsubsection{The Langmuir Timescale}

The area under the normalized concentration BTC for $T_{1}<t \leq T_{2}$, (where $T_{2}=\infty$ in the case of a one-exponential RTD), denoted $I_{T_{1}}^{T_{2}}$ (Figure 4), yields a timescale that is a good approximation to the Langmuir timescale, $\tau_{L},\left(R^{2}=0.82\right)$ (Figure 6). Note that $\tau_{L}$ is defined as the primary gyre mean residence time from the box model and:

$$
\tau_{L} \cong \int_{T_{1}}^{T_{2}} \frac{C(t)}{C(t=0)} d t
$$

Therefore, for both one- and two-exponential RTDs, $I_{T_{1}}^{T_{2}}$ is approximately the mean residence time of the primary gyre. A one-exponential RTD arises when only a single, large primary gyre dominates the STS. A two-exponential RTD arises when the STS is comprised of a large primary gyre and one or more counter-rotating secondary gyres. For a two-exponential RTD, the early time exponential decay $\left(T_{1}<t \leq T_{2}\right.$ ) results from the direct, relatively fast exchange between the primary gyre and main channel. The late time exponential decay $\left(T_{2}<t<\infty\right)$ results from the slower exchange of the smaller, slower-moving, counter-rotating gyres with the primary gyre that adds to the primary gyre residence time. This result confirms that the early time exponential decay in Figure 5c, which is due solely to the primary gyre residence time, should not be influenced by secondary gyre(s) as observed by the relatively consistent early time exponential slopes of each mean BTC between experiments and variance in late-time behavior.

In Figure 6, residuals above the best-fit line are an overestimate of the primary gyre mean residence time arising from the influence of secondary gyre residence times due to probes placed 
in close proximity to secondary gyres. The two-exponential residuals below the best-fit line are an underestimate of the primary gyre mean residence time, and arise due to the truncation of the first exponential decay at $T_{2}$ when there is a larger component of the primary gyre mean residence time within the second exponential decay.

\subsubsection{Mean Residence Timescales for one-exponential RTDs}

A one-exponential RTD does not have $\tau_{a p}$ because the influence of secondary gyres is insignificant. This occurs because either a large primary gyre dominates the STS or all probes were placed within the relatively well-mixed primary gyre and the rate of exchange with secondary gyre(s) was negligible as their residence times were substantially larger compared to the primary gyre mean residence time. However, in the field, the a priori proper placement of probes only in the primary gyre is difficult because there is uncertainty in the existence or location of secondary gyres. These secondary gyres can form due to both the STS aspect ratio and irregular STS wetted perimeter geometry, as shown in a CFD model (Figure 1). Probes placed in these poorly mixed locations add to the STS mean residence time and result in a measured apparent mean residence time for the STS, which can be observed by obtaining a twoexponential RTD.

All of the residence timescales are equal when a one-exponential RTD arises. The inverse slope of the exponential concentration decay function, $\tau_{1}$, is equal to $I_{0}^{\infty}$ (Figure 7). Therefore, $\tau_{S T S}=\tau_{L}=\tau_{1}=I_{0}^{\infty}$, and all of these timescales describe the STS mean residence time because the dominance of a primary gyre causes the STS to be relatively well mixed and to exhibit the characteristics of an ideal CSTR.

\subsubsection{Mean Residence Timescales for two-exponential RTDs}


A two-exponential RTD can be characterized by both a mean and an apparent mean residence time because the STS is comprised of a primary and one or more secondary gyres, and EC probe placement captures the effects of their residence timescales. We estimate the STS mean residence time from $I_{0}^{T_{2}}$, where $T_{2}<\infty$, by assuming that a majority of the primary gyre mean residence time resides within the first exponential decay and compute the measured apparent STS mean residence time, $\tau_{\text {ap }}$, from $I_{0}^{\infty}$ (Figure 4); thus, the STS mean residence time is always smaller than the apparent mean residence time.

The STS mean residence time computed from $I_{0}^{T_{2}}$ is approximately equivalent to the inverse slope of the first exponential decay function, $\tau_{1}$ (Figure 7), and $\tau_{a p}$ is approximately equivalent to the inverse slope of the second exponential decay function, $\tau_{2}$ (Figure 8). In Figure 7, $I_{0}^{T_{2}}$ and $\tau_{1}$ are well correlated with a small range of variability (about 30 percent) in residuals from the best fit line because the first temporal moment from (8) is truncated at $T_{2}$ to estimate the mean residence time. A better estimation of the STS mean residence time can be obtained from $\tau_{1}$ for a two-exponential RTD because this method avoids truncating the area beneath the normalized concentration curve after $T_{2}$. Similar to computing $\tau_{S T S}$ from $I_{0}^{T_{2}}$ and $\tau_{1}$, computing $\tau_{a p}$ from $I_{0}^{\infty}$ and $\tau_{2}$ in Figure 8 results in a small range of variability in residuals between methods of up to 30 percent. This variability arises because $\tau_{2}$ is estimated from the inverse slope for $T_{2} \leq t<\infty$, whereas $I_{0}^{\infty}$ comprises the area beneath the entire RTD. These methods are approximately equivalent because, in most cases, the time for initialization of the second exponential decay occurs within a relatively short period of time after injection ceases. Therefore, a better estimation of the STS measured apparent mean residence time is obtained from $I_{0}^{\infty}$, and the best estimation of the additional residence time provided by the secondary 
gyres is: $I_{0}^{\infty}-\tau_{1}$. In summary, $\tau_{L}<\tau_{S T S}=\tau_{1}<\tau_{a p}=I_{0}^{\infty}$, where the Langmuir timescale is under-estimated because of the over-estimation of the entrainment discharge from (7). This overestimation occurs because the entrainment discharge is computed using the formulation: $Q_{i n j} C_{i n j}=Q_{p m} C_{S T S}$, where $C_{S T S}>C_{p}$; therefore, the Langmuir timescale is a minimum mean residence time.

\subsection{Comparison of Mean Residence Timescales to Stream Parameters}

The ratio of the Langmuir to convective timescale is linearly correlated to the STS aspect ratio $\left(R^{2}=0.74\right)$. This suggests that the Langmuir timescale can be predicted from three stream parameters: the mean main channel velocity, the STS width, and the STS length (length of STSmain channel interface, denoted $L$ ). The Langmuir timescale was scaled by the main channel convective timescale ( $L / U$ ), which represents the travel time of fluid in the main channel over a distance equal to the STS length (i.e., time over which vortices in the shear layer will affect exchange through the STS), and compared to the $W / L$ aspect ratio (Figure 9). As both the Langmuir timescale and $W$ were scaled by $L$, this timescale is only a function of the mean channel velocity and STS width. Mean depths at the STS entrance and in the STS were not included because they were nearly the same at field sites.

The apparent mean residence time and STS mean residence time both have good linear correlations to physically-based stream parameters using Uijttewaal et al.'s formulation of the mean residence time (10) (Figure 10 and 11). There is a strong correlation between $\tau_{a p}$ and physically-based parameters $\left(R^{2}=0.82\right)$. The entrainment coefficient, $k$ (inverse slope in Figure 10), is $0.016 \pm 0.007$ for all data, and $0.019 \pm 0.006$ for the field measurements. The STS mean residence time computed from $\tau_{1}$ also has a strong linear correlation to physically-based stream 
parameters (Figure 11) $\left(R^{2}=0.75\right)$ with $k=0.031 \pm 0.009$, which predicts exchange that is about two times faster than the apparent mean residence time.

\section{Discussion}

\subsection{Assumptions of the Box Model for STS}

The box model assumes (1) the primary and secondary gyres are well-mixed; (2) a steady flow field; and (3) neither sources nor sinks exist other than the pump (specified as a source); however, each of these assumptions is violated in the field to some degree. First, natural lateral STS are not comprised of perfectly well mixed gyres. Gyres have a nearly stagnant inner core and higher velocities toward their outer region, which disproportionately disperses mass that becomes entrained [Kang and Sotiropoulos, 2011]. A tracer entering a gyre can either disperse radially relatively fast or become entrained in the slower, nearly stagnant inner core with longer residence times. Second, exchange of mass and momentum through natural lateral STS occurs because turbulent mixing processes are inherently unsteady. The flow dynamics of exchange in natural lateral STS are complex due to velocity and pressure fluctuations in the shear layer that interact with and produce unsteady recirculating flow in the STS. However, we assume that these fluctuations are small relative to the mean velocity and pressure flow fields, and are rapid relative to the exchange timescales, so that we can solve for a steady state solution. This assumption is based on literature review of flow past lateral cavities in the range of $W / L$ and $R e$ studied, where similar flow features are observed and the flow structures in the mean do not change significantly [Uijttewaal et al., 2001; Weitbrecht et al., 2008]. Lastly, assuming neither sources nor sinks exist in the STS (other than the pump) ignores hyporheic exchange through the streambed. This assumption was made because (1) as observed in the field, natural lateral STS have streambeds comprised predominantly of fine silts and clays, which have relatively low 
permeability; (2) hyporheic exchange processes are slow and have relatively long timescales of exchange that range from hours to days [Harvey and Bencala, 1993; Boulton et al., 1998; Harvey and Wagner, 2000; Haggerty et al., 2002; Wörman et al., 2002; 2007; Gooseff et al., 2003; Dent et al., 2007; Cardenas, 2008; Cardenas et al., 2008; Bencala, 2011]; and (3) the timescale of the $\mathrm{NaCl}$ injection experiments was relatively short (on the order of 10 to 30 minutes per experiment).

The box model is a 2-D representation of the 3-D flow field in natural lateral STS studied. The box model is 2-D because the depth is shallow at the STS field sites where the main channel depth is nearly the same as the STS depth (Table 1). In cases where STS depth is close to channel depth, eddies in the shear layer are quasi-two dimensional, and in cases where the STS depth significantly differs from the channel depth, fully three-dimensional eddies form in the shear layer [McCoy et al., 2007; 2008]. Therefore, for the field sites studied, vertical momentum flux does not play a significant role in residence time and the box model can be represented as 2-D.

\subsection{The Langmuir Timescale}

The Langmuir timescale (primary gyre mean residence time for STS) is the minimum mean residence time and has implications for stream ecology and restoration. For example, stream restoration projects typically emplace in-stream structures that increase physical and biological diversity; however, different structures may enhance the growth of different types of biotic communities because residence times generated by flow conditions and the structures' aspect ratios will affect the nutrient uptake capabilities of the stream [Argerich et al., 2011]. As the minimum residence timescale scales with mean channel velocity and STS width, these two 
parameters can be used to predict the minimum residence time within lateral STS. This will be a powerful tool because predicting this timescale has minor data collection requirements.

\subsection{STS Mean and Apparent Mean Residence Time}

The STS mean residence time-i.e., the mean residence time that would be observed in the main channel from a conservative tracer test-is only dependent on the primary gyre mean residence time. The STS mean residence time is best estimated by the inverse slope of the first exponential decay curve, $\tau_{1}$. The Langmuir timescale is the primary gyre mean residence time (as derived from the box model) for a one-exponential RTD, but this timescale is underestimated for a two-exponential RTD due to the formulation used to compute the entrainment discharge: $Q_{i n j} C_{i n j}=Q_{p m} C_{S T S}$, where $C_{S T S}>C_{p}$.

The secondary gyres add to the apparent measured mean residence time if these gyres’ concentrations are included in the average. It is the volumes, not residence times, of the secondary gyres that always influence the mean residence time of the primary gyre (refer to (5)). Consequently, estimation of STS mean residence time using tracer measurements within the STS zone is subject to error unless sensor emplacement in secondary gyres can be avoided.

\subsection{Flow Field Physics in Natural Lateral STS and Implications for a 1-exponential RTD}

Aspect ratios $(W / L)$ less than 0.5 result in the development of a two-gyre recirculation pattern with the secondary gyre forming in the upstream corner (see Figure 1). Aspect ratios $0.5<W / L<1.5$ result in the development of a one-gyre recirculation pattern with possible small secondary gyres in the upstream and downstream corners near the STS bank [Weitbrecht, 2004; McCoy et al., 2008]. These general rules apply to idealized STS geometries, such as rectangular

cavities. In natural systems, similar patterns develop, with the exception that more secondary gyres can form because of irregular wetted perimeters due to rocky banks and vegetation. The 
production of a one-exponential RTD does not necessarily imply that the STS is comprised of only a single primary gyre, but that the STS is dominated by the primary gyre and the effect of smaller counter-rotating gyres is negligible because either their volumes or exchange rates with the primary gyre are sufficiently small. Note that for an ideal (well-mixed) CSTR, $\tau_{L}=\tau_{\text {STS }}=\tau_{1}$ [Nauman, 1981]. Therefore, we can assume that one-exponential RTDs apply to lateral STS that are sufficiently well-mixed.

\subsection{Scaling Relationships}

Scaling from a single lateral STS to a distribution along a reach is an important application. While a detailed treatment of this is beyond the scope of this paper, two comments can be made. Since the application of the scaling law is an important consideration in scaling, we limit our comments to conservative solute transport.

First, in the unlikely case that all STS zones are of the same size and shape, the conservative solute's transport will be governed by $\tau_{S T S}=\tau_{1}$ and $A_{s} / A$, and $A_{s} / A$ will be determined by a simple summation of STS volumes. Once these values are determined, the models in the literature for a single timescale of exchange [e.g., Bencala and Walters, 1983 and subsequent references] will be applicable. The breakthrough curve will be a classical advectiondispersion curve with an exponential tail governed by $\tau_{\text {STS }}=\tau_{1}$ and $A_{s} / A$.

Second, in the more likely case of a distribution of sizes and shapes of STS zones, the distribution must be quantified and then properly applied at the reach scale. For the sake of illustration, let us assume a power-law distribution of STS widths but (unrealistically) all other parameters are constant. Furthermore, let us assume that transient storage is dominated by STS. Let us assume a pdf of STS volume that takes the form $b w^{3-a}$, where $b$ is a scaling parameter with units $\left[L^{a-4}\right]$ and a value such that the pdf integrates to 1 . This pdf will generate a pdf of 
inverse timescales $\tau_{\text {STS }}{ }^{-1} \sim w^{a-3}$. Haggerty et al. [2000] derived the relationship between a distribution of inverse timescales (rate coefficients) and a breakthrough curve. This distribution of STS widths will generate a breakthrough curve with power-law late-time behavior, $C(t) \sim t^{-a}$. Note that our use of $a$ here is equivalent to Haggerty et al.'s $k$, which we cannot use because of variable duplication. For example, consider a pdf of widths $\sim w^{1}$, which is a distribution of STS zones where the volume fraction of the STS is linearly proportional to the STS width. This will generate a breakthrough curve $C(t) \sim t^{-2}$, up to the $t \sim \tau_{\text {STS }}{ }^{-1}$ given by (9) for the largest STS width, at which time the breakthrough curve will begin to decay exponentially.

\subsection{The Entrainment Coefficient}

An entrainment coefficient of $0.19 \pm 0.006$ predicted for $\tau_{a p}$ is within the range of laboratory experiments (Table 2) of open channel flow past lateral rectangular cavities, whereas an entrainment coefficient of approximately $0.031 \pm 0.009$ for $\tau_{\text {STS }}$ is on the higher end of previously measured values. However, for a number of reasons, we postulate that the $\tau_{\text {STS }}$ $k \approx 0.031$ is a better predictive value for computing mean residence times of natural lateral STS studied. First, laboratory experiments use more ideal geometries than observed in field configurations. Natural lateral STS, as observed in the field, typically are shallow (i.e., bed friction plays a role in slowing exchange) and have irregular wetted perimeters that are able to form a greater number of secondary gyres compared to lab experiments. As these additional gyres are small and are located within the shallowest regions of the STS (Figure 1b), their residence times typically will have less of an influence on the primary gyre mean residence time, causing a faster exchange rate through the STS. Second, laboratory studies of flow past a series of lateral cavities typically take experimental measurements starting from the fourth through 
sixth cavity downstream to ensure a fully developed shear layer [Uijttewaal et al., 2005]. This yields consistent exchange rates among cavities adjacent to the fully developed shear layer [Weitbrecht et al., 2008]. The first few cavities (i.e., the cavities farthest upstream in a series of lateral cavities that are more representative of a natural STS) are adjacent to an unstable (not fully developed) shear layer, which causes each of these cavities to have differing exchange rates because the dimensions of the primary recirculating gyre decreases downstream, allowing secondary gyres to increase in size [McCoy et al., 2008]. Thus, laboratory measurements were collected from cavity flow fields with smaller primary gyres and larger secondary gyres for similar cavity aspect ratios (W/L), which increases mass entrainment and mean residence time and decreases mass exchange. Lastly, a study by Seo and Maxwell [1992] constructed a pool and riffle stream in a large experimental flume by placing gravel on the riffles to simulate STS geometries representative of natural streams. This study obtained an empirical entrainment coefficient of $0.037 \pm 0.032(n=12)$, which is close to our value of 0.031 . Comparison of natural lateral STS to laboratory experiments is difficult because few studies have been done on turbulent open channel flow past open lateral cavities in environments representative of streams. However, the relatively narrow range of values estimated for $k$ from lab experiments and field measurements indicate that the STS mean residence time may be predicted using Uijttewaal et al.'s equation (10). Note that the predictive relationship may not be a universal relationship representative of all lateral STS in natural streams, but will be applicable for a range of $R e$ and STS geometries. Other predictive relationships also may be needed to represent STS with slightly differing flow fields, such as STS characterized by shear layers that do not span the entire STS length or STS generated by in-stream flow obstructions, such as logs, where flow 
enters the STS both through a shear layer and over the top of the log, which is analogous to the case of flow past a submerged groyne.

An explanation for the variability of $k$ between laboratory and field experiments is elusive and is a topic worthy of further research. We hypothesize that other parameters not accounted for in (10), such as streambed and streambank roughness characteristics and vegetative drag may also influence $k$ and, therefore, may help to explain (and possibly reduce) some of the variability. The roughness characteristics of natural lateral STS typically will be rougher than their more ideal counterparts studied in laboratory flumes for given flow and geometry conditions. Increased roughness likely will decrease the vorticity in the STS and subsequently decrease mass exchange and increase STS mean residence time, which may reduce the variability in $k$ between lab and field experiments; however, an exact relationship has not been identified to date.

\section{Summary and Conclusions}

The purpose of this paper is to define the appropriate mean residence time of lateral STS in small streams for a range of flow conditions $(5,000 \leq R e \leq 200,000)$ and STS geometries $(0.2$ $\leq W / L \leq 0.75$ ) in a way that will guide quantitative field measurements, and to relate residence timescales to field-measureable parameters. Five study objectives were defined: (1) to develop a theoretical mean residence time for lateral STS as a basis for comparing residence timescales defined in the literature; (2) to quantitatively relate residence timescales to determine the appropriate metric for the STS mean residence time; (3) to determine when an apparent mean residence time arises; (4) to relate residence timescales to physically measureable parameters in the field to develop predictive relationships; and (5) to provide physical explanations for 
different residence timescales and for the occurrence of one- or two-exponential RTDs using fluid dynamics.

Two theoretical residence timescales were derived to characterize natural lateral STS: a mean residence time and an apparent mean residence time. The most appropriate metric for estimating the STS mean residence time is the inverse slope of the first exponential decay, $\tau_{1}$. The STS mean residence time, $\tau_{\text {SIS }}$, is the primary gyre mean residence time. An apparent measured mean residence time, that is larger than the STS mean residence time, arises when secondary gyres are inadvertently included in the mean residence time calculation due to the placement of probes within these poorly mixed locations.

The Langmuir timescale is the minimum mean residence time of lateral STS. This result has important implications for stream ecology and restoration projects because this timescale may be used in the design of in-stream structures typically emplaced into streams to enhance biodiversity. The Langmuir timescale, when scaled by the main channel convective timescale, $L / U$, has a linear correlation to the STS $W / L$. From this correlation, the Langmuir timescale can be predicted using two stream parameters: the mean channel velocity, and STS width.

Natural lateral STS are characterized by one- and two-exponential RTDs. Oneexponential RTDs arise when a large primary gyre dominates the STS. Two-exponential RTDs arise when the STS is comprised of a large primary gyre and a number of smaller, counterrotating secondary gyres generated by an irregular boundary. The early time exponential decay is due to direct, relatively fast exchange between the primary gyre and main channel, whereas the late time exponential decay is due to the combined effects of slower exchange of the smaller, slower-moving, counter-rotating gyres with the primary gyre and the exchange of the primary gyre with the main channel. 
The STS mean residence time was estimated using the predictive relationship developed by Uijttewaal et al. [2001] based on field-measureable stream parameters. An entrainment coefficient of $k=0.031 \pm 0.009$ was estimated from the field data using the STS mean residence time. Variability in estimated values of $k$ between laboratory and field experiments may possibly be explained (and reduced) by accounting for other physical factors not currently in the predictive relationship, such as roughness characteristics of the STS bank and bed and vegetative drag, and this is a topic worthy of further research.

\section{Appendix A.}

\section{A.1 Data Collection for RANS CFD Model}

Detailed morphological and flow field measurements were taken of a lateral STS at Site 1P. STS morphology and water surface were surveyed using a Topcon GTS-230W total station [Topcon Corporation, 2008] to obtain a grid for the CFD model. The maximum streamwise distance surveyed was $1 \mathrm{~m}$ upstream and $2 \mathrm{~m}$ downstream. Streambed topology was surveyed with a sample spacing density of about 3-5 cm between point measurements in the STS and with a sample spacing density of about $5-10 \mathrm{~cm}$ between points in the main channel. The mean water surface was obtained by randomly surveying points with a sampling density of about 10 points $/ \mathrm{m}^{2}$.

Instantaneous, three-dimensional velocities were measured in the main channel and shear layer using an acoustic Doppler velocimeter (ADV) [SonTek, 2001], which has a $10 \mathrm{~cm}$ distance from the transducer and 25-Hz sampling rate. Main channel velocities were measured along one transect (normal to flow) at about $1 \mathrm{~m}$ upstream of the STS zone, and shear layer velocities were measured along one transect (parallel to flow) at time durations of $60 \mathrm{~s}$ for each measurement. 
Mean flow and turbulence quantities (i.e., turbulence intensity and kinetic energy) were obtained from the ADV data and used to validate the RANS CFD model.

\section{A.2 Description of RANS CFD Model}

The 3-D RANS CFD model has an unstructured grid and flow boundary conditions specified $1 \mathrm{~m}$ upstream and downstream of the STS (Figure 1b; zoomed in plan view image). The grid geometry was formulated in the commercial grid generation software, Pointwise. A periodic flow boundary condition (based on the mean channel velocity of $0.35 \mathrm{~m} / \mathrm{s}$ ) was used to obtain a fully developed velocity profile inlet boundary condition. A velocity profile inlet boundary condition and a pressure outlet boundary condition were specified upstream and downstream of the STS, respectively. A no-slip boundary was specified for the streambed and banks and the water surface was specified as a slip boundary.

A commercial RANS finite volume solver, Star-CCM+, was used to solve the RANS equations with the standard $k-\varepsilon$ turbulence closure model and wall functions (see Wilcox [2006] for further details). Both the SST Mentor $k-\Omega$ and $k-\varepsilon$ models were used for detailed verification tests on idealized lateral rectangular storage zone geometries at the same $R e$ and similar $W / L$. The verification tests show good agreement with experimental as well as large-eddy simulation results published in the literature [Drost et al., 2012]. The flow prediction did not significantly change when using either turbulence closure. For the relatively complex 3-D STS geometry, the $k-\varepsilon$ model was used mainly because this closure model was easier to obtain a converged solution compared to the SST Mentor $k-\Omega$ model. A grid refinement study was done where the number of control volumes increased from approximately 7 million (0.02 to 0.04 m cell size), to 23 million ( 0.01 to $0.02 \mathrm{~m}$ cell size), and 68 million ( 0.005 to $0.01 \mathrm{~m}$ cell size) 
with each cell reduced in size by half between grids. The flow structure, including the number of gyres, and the mean velocity field did not change when the grid was refined.

\section{Acknowledgments:}

This work was supported by the National Science Foundation, EAR 09-43570. Field assistance was provided by Nick Kules, Cian Gipson, Alex Wick, Steven Ward, Mousa Diabat, and Nathan Pauley. We would like to thank the reviewers of this manuscript for their thoughtful and exceptionally high quality feedback that has significantly improved the outcome of this manuscript.

\section{Notation}

A Main channel cross-sectional area, $\left[\mathrm{L}^{2}\right]$

$A_{s} \quad$ STS cross-sectional area, $\left[\mathrm{L}^{2}\right]$

$C$ STS concentration, $\left[\mathrm{ML}^{-3}\right.$ ]

$C_{i n j} \quad$ Mean concentration of the injected tracer, $\left[\mathrm{ML}^{-3}\right]$

$C_{m}$ Main channel concentration, $\left[\mathrm{ML}^{-3}\right]$

$C_{p}$ Primary gyre concentration, $\left[\mathrm{ML}^{-3}\right]$

$C_{s}$ Secondary gyre concentration, $\left[\mathrm{ML}^{-3}\right]$

$C_{\text {STS }}$ Mean STS concentration, $\left[\mathrm{ML}^{-3}\right]$

$d_{E} \quad$ Mean water depth in shear layer, [L]

$d_{\text {SIS }} \quad$ STS water depth, [L]

E Entrainment velocity, $\left[\mathrm{LT}^{-1}\right]$

$F\left(t_{r}\right) \quad$ STS residence time distribution, $\left[\mathrm{T}^{-1}\right]$

I Integration beneath normalized concentration curve, [T]

$I_{0}^{T_{2}} \quad$ Integration for $0 \leq t<T_{2},[\mathrm{~T}]$

$I_{T_{1}}^{T_{2}} \quad$ Integration for $T_{1}<t \leq T_{2}$, [T] 
$I_{0}^{\infty} \quad$ Integration for $0 \leq t<\infty,[\mathrm{T}]$

$k$ Dimensionless entrainment coefficient, [-]

$L$ Length at main channel-STS interface (shear layer), [L]

$Q_{i n j}$ Volumetric injection rate from external source, $\left[\mathrm{L}^{3} \mathrm{~T}^{-1}\right]$

$Q_{p s} \quad$ Volumetric exchange between primary and secondary gyre, $\left[\mathrm{L}^{3} \mathrm{~T}^{-1}\right]$

$Q_{p m} \quad$ Volumetric exchange between main channel and primary gyre, $\left[\mathrm{L}^{3} \mathrm{~T}^{-1}\right]$

$t$ Current time, [T]

$t_{i} \quad$ Time of initial entrainment, [T]

$t_{r}$ Current residence time of solute particle, [T]

$T_{1}$ Time for initiation of first exponential decay, [T]

$T_{2}$ Time for initiation of second exponential decay, [T]

$U$ Mean main channel velocity, $\left[\mathrm{LT}^{-1}\right]$

$V \quad$ Volume, $\left[\mathrm{L}^{3}\right]$

$V_{p} \quad$ Primary gyre volume, $\left[\mathrm{L}^{3}\right]$

$V_{s} \quad$ Secondary gyre volume, $\left[\mathrm{L}^{3}\right]$

$V_{\text {STS }} \quad$ STS volume, $\left[\mathrm{L}^{3}\right]$

$W \quad$ STS width, [L]

$W_{p} \quad$ Wetted perimeter, [L]

$\beta_{s} \quad$ Fraction of STS volume occupied by secondary gyres, [-]

$\tau$ Characteristic timescale of exponential decay, [T]

$\tau_{a p} \quad$ Measured apparent STS mean residence time, [T]

$\tau_{L} \quad$ Langmuir timescale (Eqn 6), [T]

$\tau_{s}$ Mean residence time of secondary gyre, [T]

$\tau_{\text {STS }}$ STS mean residence time, [T]

$\tau_{1}$ Inverse slope of first exponential decay function, [T]

$\tau_{2}$ Inverse slope of second exponential decay function, [T] 


\section{References}

Anderson, E.J., and M.S. Phanikumar, (2011), Surface storage dynamics in large rivers: Comparing three-dimensional particle transport, one-dimensional fractional derivative, and multirate transient storage models, Water Resour. Res., 47, W09511, doi:10.1029/2010WR010228.

Argerich, A., E. Martí, F. Sabater, R. Haggerty, and M. Ribot (2011), Influence of transient storage on stream nutrient uptake based on substrata manipulation, Aquat. Sci., doi: 10.0007/s00027-011-0184-9.

Aris, R. (1956), On the Dispersion of a Solute in a Fluid Flowing through a Tube, P. Roy. Soc. Lond A, 235, 67-77, doi: 10.1098/rspa.1956.0065.

Aris, R. (1958), On the dispersion of linear kinematic waves, P. Roy. Soc. Lond A, 245(1241), 268-277, doi:10.1098/rspa.1958.0082

Battin, T. J., L.A. Kaplan, J.D. Newbold, and S.P. Hendricks (2003), A mixing model analysis of stream solute dynamics and the contribution of hyporheic zone to ecosystem function, Freshwater Biol., 48, 995-1014.

Bellucci, A., G. Buffoni, A. Griffa, and E. Zanbianchi (2001), Estimation of residence times in semi-enclosed basins with steady flows, Dynam. Atmos. Ocean, 33, 201-218.

Bencala, K.E., and R.A. Walters (1983), Simulation of solute transport in a mountain pool-andriffle stream: A transient storage model, Water Resour. Res., 19, 718-724.

Bencala, K.E., V.C. Kennedy, G.W. Zellweger, A.P. Jackman, and R.J. Avanzino (1984), Interactions of solutes and streambed sediments, 1, An experiment analysis of cation and anion transport in a mountain stream, Water Resour. Res., 20, 1797-1803.

Bencala, K.E. (2011), Stream-Groundwater Interactions, In: Treatise on Water Science, P. Wilderer (ed.), 2, pp. 537-546 Oxford: Academic Press.

Boano, R., R. Revelli, and L. Ridol (2011), Water and solute exchange through .at streambeds induced by large turbulent eddies, J. Hydrol., 402, 290-296.

Boulton, A. J., S. Findlay, P. Marmonier, E.H. Stanley, and H.M. Valett (1998), The functional significance of the hyporheic zone in streams and rivers, Annu. Rev. Ecol. Sys., 29, 59-81.

Botter, G., E. Bertuzzo, and A. Rinaldo (2011), Catchment residence and travel time distributions: The master equation, Geophys. Res. Lett., 38, L11403, doi:10.1029/2011GL047666.

Briggs, M. A., M.N. Gooseff, C.D. Arp, and M.A. Baker (2009), A method for estimating surface transient storage parameters for streams with concurrent hyporheic storage, Water Resour. Res., 45, W00D27, doi:10.1029/2008WR006959.

Buffham, B.A. (1985), Residence-time distributions in regions of steady-flow systems, Nature, 314, 606-608.

Buffoni, G., P. Falco, A. Griffa, and E. Zambianchi (1997), Dispersion processes and residence times in a semi-enclosed basin with recirculating gyres, An application to the Tyrrhenian Se, J. Geophys. Res., 102(C8), 18.699-18,713.

Cardenas, M. B. (2008), Surface water-groundwater interface geomorphology leads to scaling of residence times, Geophys. Res. Lett., 35, L08402, doi:08410.01029/02008GL033753.

Cardenas, M. B., J.L. Wilson and R. Haggerty (2008), Residence time of bedform-driven hyporheic exchange, Adv. Water Res., 31, 1382-1386, doi:1310.1016/j.advwatres.2008.1307.1006. 
Cerling, T.E., S.J. Morrison, and R.W. Sobocinski (1990), Sediment-water interaction in a small stream: Adsorption of ${ }^{137}$ Cs by bed load sediments, Water Resour. Res., 26, 1165-1176.

Chang, K., G. Constantinescu, and S.O. Park (2011), Analysis of the flow and mass transfer processes for the incompressible flow past an open cavity with a laminar and a fully turbulent incoming boundary layer, J. Fluid Mech., 561, 113-145, doi:10.1017/S0022112006000735.

Chang, K., G. Constantinescu, and S.O. Park (2007), Purging of a neutrally buoyant or a dense miscible contaminant from a rectangular cavity. II: Case of an incoming fully turbulent overflow, J. Hydraul. Eng., 133(4), 373-385, doi:10.1061/(ASCE)07339429(2007)133:4(373).

Cheng, M., and K.C. Hung (2006), Vortex structure of steady flow in a rectangular cavity, Comput Fluids, 35, 1046-1062.

Chiang, T. P., R.R. Hwang, and W.H. Sheu (1997), On end-wall corner vortices in a lid-driven cavity, Trans. ASME: J. Fluids Eng, 119, 201-204.

Chiang, T. P., W.H. Sheu, and R.R. Hwang (1998), Effect of Reynolds number on the eddy structure in a lid-driven cavity, Intl. J. Numer. Meth. Fluids, 26, 557-579.

Constantinescu, G., A. Sukhodolov, and A. McCoy (2009), Mass exchange in a shallow channel flow with a series of groynes: LES study and comparison with laboratory and field experiments, Environ. Fluid Mech., 9, 587-615, DOI 10.1007/s10652-009-9155-2.

Constantinescu, G., S. Miyawaki, and B. Rhoads (2011), The structure of turbulent flow at a river confluence with momentum and velocity ratios close to one: Insight provided by an eddy-resolving numerical simulation, Water Resour. Res., 47, W05507, 1-16.

Cunningham, J. A., and P. V. Roberts (1998), Use of temporal moments to investigate the effects of nonuniform grain-size distribution on the transport of sorbing solutes, Water Resour. Res., 34(6), 1415-1425.

Danckwerts, P. V. (1953), Continuous-flow systems: Distribution of residence times, Chem. Eng. Sci., 2, 1-13.

Dent, C. L., N.B. Grimm, E. Martí, J.W. Edmonds, J. C. Henry J.R. and Welter (2007), Variability in surface-subsurface hydrologic interactions and implications for nutrient retention in an arid-land stream, J. Geophys. Res., 112, G04004, doi:04010.01029/02007JG000467.

Drost, K., T. Jackson, R. Haggerty and S.V. Apte (2012), RANS predictions of turbulent scalar transport in dead zones of natural streams, FEDSM2012-72380, Proceedings of the ASME Fluid Engineering Summer Meeting, Peurto Rico, July 2012.

Engelhardt, C., A. Krüger, A. Sukhodolov, and A. Nicklisch (2004), A study of phytoplankton spatial distributions, flow structure and characteristics of mixing in a river reach with groynes: J. Plankton Res., 26(11), 1351-1366.

Ensign, S. H., and M.W. Doyle (2005), In-channel transient storage and associated nutrient retention: Evidence from experimental manipulations, Limnol. Oceanogr., 50(6), 17401751.

Feriziger, J.H., and M. Perić (2002), Computational Methods for Fluid Dynamics, $3^{\text {rd }}$ ed., Springer, Berlin, Germany.

Fogler, H.S. (2006), Elements of Chemical Reaction Engineering, $4^{\text {th }}$ ed., Prentice Hall, New York, New York. 
Gooseff, M.N., S.M. Wondzell, R. Haggerty and J. Anderson (2003), Comparing transient storage modeling and residence time distribution (RTD) analysis in geomorphically varied reaches in the Lookout Creek basin, Oregon, USA, Adv. Water Res., 26(9), 925-93.

Gooseff, M.N., J. LaNier, R. Haggerty, and K. Kokkeler (2005), Determining in-channel (dead zone) transient storage by comparing solute transport in a bedrock channel-alluvial channel sequence, Oregon, Water Resour. Res., 41, W06014, doi:10.1029/2004WR003513.

Guermond, J.-L., C. Migeon, G. Pineau and L. Quartapelle, (2002), Start-up flows in a threedimensional rectangular driven cavity of aspect ratio 1:1:2 at $\mathrm{Re}=1000$, J. Fluid Mech., 450, 169-199.

Haggerty, R., S.A. McKenna and L. Meigs (2000), On the late-time behavior of tracer test breakthrough curves, Water Resour. Res., 36(12), 3467-3479.

Haggerty, R., S.M. Wondzell, and M.A. Johnson (2002), Power-law residence time distribution in the hyporheic zone of a 2nd-order mountain stream, Geophys. Res. Lett., 29(13), 1640, doi:10.1029/2002GL014743.

Haggerty, R., and P. Reeves (2002), STAMMT-L version 1.0 user's manual: Sandia National Laboratories, Albuquerque, New Mexico, 76 p.

Hall, R.O., E.S. Bernhardt, and G.E. Likens (2002), Relating nutrient uptake with transient storage in forested mountain streams, Limnol. Oceanogr., 47, 255-265.

Harvey, J. W. K.E. Bencala (1993), The effect of streambed topography on surface subsurface water exchange in mountain catchments, Water Resour. Res., 29(1), 89-98.

Harvey, C.F., and S.M. Gorelick (1995), Temporal moment-generating equations: Modeling transport and mass transfer in heterogeneous aquifers, Water Resour. Res., 31(8), 18951911.

Harvey, J. W., B.J. Wagner, and K.E. Bencala (1996), Evaluating the reliability of the stream tracer approach to characterize stream-subsurface water exchange, Water Resour. Res., 32(8), 2441-2451.

Harvey, J. W., and B.J. Wagner (2000), Quantifying hydrologic interactions between streams and their subsurface hyporheic zones, in Streams and Ground Waters, edited by J.B. Jones, and P.J. Mulholland, p. 425, Academic Press, San Diego, California.

Hays, J.R. (1966), Mass Transport Mechanisms in Open Channel Flow, Ph.D Dissertation, Vanderbilt University, Nashville, Tennessee.

Hinterberger, C., J. Fröhlich, W. Rodi (2007), Three-Dimensional and Depth-Averaged LargeEddy Simulations of Some Shallow Water Flows, J. Hydraul. Eng., 133(8), 857-872.

Houser, J. N., D. W. Bierman, R. M. Burdis, and L. A. Soeken-Gittinger (2010), Longitudinal trends and discontinuities in nutrients, chlorophyll, and suspended solids in the Upper Mississippi River: Implications for transport, processing, and export by large rivers, Hydrobiologia, 651(1), 127-144.

Kang, S. and F. Sotiropoulos (2011), Flow phenomena and mechanisms in a field-scale experimental meandering channel with a pool-riffle sequence: Insights gained via numerical simulation Flow phenomena and mechanisms in a field-scale experimental meandering channel with a pool-riffle sequence: Insights gained via numerical simulation, J. Geophys. Res., 116, doi:10.1029/2010JF001814.

Kasahara, T., and S.M. Wondzell (2003), Geomorphic controls on hyporheic exchange flow in mountain streams, Water Resour. Res., 39(1), 1005, doi:1010.1029/2002WR001386. 
Keylock, C. J., R.J. Hardy, D.R. Parsons, R.I. Ferguson, S.N. Lane, and K.S. Richards (2005), The theoretical foundations and potential for large-eddy simulation (LES) in fluvial geomorphic and sedimentological research, Earth-Sci Rev., 71, 271-304.

Kimura, I., and T. Hosada (1997), Fundamental properties of flows in open channels with dead zone, J. Hydraul. Eng., 123(2), 98-107.

Knisely, C. and Rockwell, D. (1982), Self-sustained low-frequency components in an impinging shear layer, J. Fluid Mech., 116, 157-186.

Koseff, J. R. and R.L. Street (1982), Visualization studies of a shear driven three-dimensional recirculating flow, AIAA/ASME Thermophysics and Heat Transfer Conference, St Louis, 2331.

Koseff, J. R. and R.L. Street (1984a), Visualization studies of a shear driven three-dimensional recirculating flow. Trans. ASME: J. Fluids Eng, 106, 21-29.

Koseff, J. R. and R.L. Street (1984b), On end wall effects in a lid-driven cavity flow, Trans. ASME: J. Fluids Eng., 106, 385-389.

Koseff, J. R. and R.L. Street (1984c), The lid-driven cavity flow: a synthesis of qualitative and quantitative observations, Trans. ASME: J. Fluids Eng, 106, 390-398.

Kozerski, H.P., R. Schwartz, and T. Hintze (2006), Tracer measurements in groyne fields for the quantification of mean hydraulic residence times and of the exchange with the stream, Acta Hydroch. Hydrob., 34, 188-200.

Kurzke, M., V. Weitbrecht, and G.H. Jirka (2002), Laboratory concentration measurements for determination of mass exchange between groin fields and main stream, paper presented at IAHR Conference, 'River Flow', Louvain de la Neuve, Belgium.

Lancaster, J., and A.G. Hildrew (1993), Characterizing in-stream flow refugia, Can. J. Fish. Aquat. Sci., 50(8), 1663-1675.

Langmuir, I. (1908), The velocity of reactions in gases moving through heated vessels and the effect of convection and diffusion, J. Am. Chem. Soc., 30, 1742-1754.

Lautz, L. K., and D.I. Siegel (2006), Modeling surface and ground water mixing in the hyporheic zone using MODFLOW and MT3D, Adv. Water Resour., 29(11), 1618-1633.

Lautz, L. K., and D.I. Siegel (2007), The effect of transient storage on nitrate uptake lengths in streams: An inter-site comparison, Hydrol. Process., 21, 3533-3548.

Lawson, S. J. and G N Barakos (2011), Review of numerical simulations for high-speed, turbulent cavity flows, Aerosp. Sci. Technol., 47(3), 186-216.

Lin, J.C., and D. Rockwell (2001), Organized oscillations of initially turbulent flow past a cavity, AIAA J., 39(6), 1139-1151.

Luo, J., O.A. Cirpka, M. Dentz, and J. Carrera (2008), Temporal moments for transport with mass transfer described by an arbitrary memory function in heterogeneous media, Water Resour. Res., 44, W01502, doi: 10.1029/2007WR006262.

Marsh-McBirney (1990), FLO-MATE Model 2000 Portable Flowmeter Instruction Manual, Marsh-McBirney, Inc., Frederick, Maryland.

McCoy, A., G. Constantinescu, and L. Weber (2006), Exchange processes in a channel with two vertical emerged obstructions, Flow Turbul. Combust., 77, 97-126, doi:10.1007/s10494-0069039-1.

McCoy, A., G. Constantinescu, and L. Weber (2007), A numerical investigation of coherent structures and mass exchange processes in channel flow with two lateral submerged groynes, Water Resour. Res., 43, W05445, doi:05410.01029/02006WR005267. 
McCoy, A., G. Constantinescu, and L. Weber (2008), Numerical investigation of flow hydrodynamics in a channel with a series of groynes, J. Hydraul. Eng., 134(2), 157-172.

Moin, P., and K. Mahesh (1998), Direct numerical simulation: a tool in turbulence research: Annu Rev. Fluid Mech., 30, 539-578.

Morrice, J.A., H.M. Valett, C.N. Dahm, and M.E. Campana (1997), Alluvial characteristics, groundwater-surface water exchange and hydrologic retention in headwater streams: Hydrol. Process., 11, 253-267.

Mulholland, P. J., E.R. Marzolfl, J.R. Webster, D.R. Hart, and S.P. Hendricks (1997), Evidence that hyporheic zones increase heterotrophic metabolism and phosphorus uptake in forest streams, Limnol. Oceanogr., 42, (3), 443-451.

Muto, Y., H. Imamoto, and T. Ishigaki (2000), Turbulence Characteristics of a Shear Flow in an Embayment Attached to a Straight Open Channel, paper presented at Proceedings of the $4^{\text {th }}$ International Conference on HydroScience and Engineering, IAHR, Seoul, Korea.

Nauman, E.B. (1981), Residence time distributions in systems governed by the dispersion equation, Chem. Eng. Sci., 36, 957-966.

Nauman, E.B. (1985), Residence time distributions and micromixing, Chem. Eng. Comm., 8, 53131.

Nepf, H. (1999), Drag, turbulence, and diffusion in flow through emergent vegetation, Water Resour. Res., 35(2), 479-489.

Nordin E. and B.M. Troutman, (1980), Longitudinal dispersion in rivers: the persistence of skewness in observed data, Water Resour. Res., 16, 123-128.

O’Connor, B.L., M. Hondzo and J.W. Harvey (2010), Predictive modeling of transient storage and nutrient uptake: Implications for stream restoration, J. Hydraul. Eng, 136(12), 10181032.

Ozalp, C., A. Pinarbasi and B. Sahin (2010), Experimental measurement of flow past cavities of different shapes, Exp. Therm. Fluid Sci., 34, 505-515.

Patwardhan, A.W. (2001), Prediction of Residence Time Distribution of Stirred Reactors, Ind. Eng. Chem. Res., 40, 5686-5695.

Phanikumar, M.S., I. Islam, C. Shen, D.T. Long, and T.C. Voice (2007), Separating surface storage from hyporheic retention in natural streams using wavelet decomposition of acoustic Doppler current profiles, Water Resour. Res., 43, W05406, doi:10.1029/2006WR005104.

Runkel, R. L. (1998), One-dimensional transport with inflow and storage (OTIS): A solute transport model for streams and rivers, U. S. Geol. Surv. Water Res. Inv. Rep., 98 - 4018, Denver, Colorado, 73 p.

Runkel, R.L. (2002), A new metric for determining the importance of transient storage, J. North Am. Benthol. Soc., 21(4), 529-543.

Roussinova, V., and S.M. Kresta (2008), Comparison of Continuous Blend Time and Residence Time Distribution Models for a Stirred Tank, Ind. Eng. Chem. Res., 47, 3532-3539.

Salehin, M., A.I. Packman, and A. Wörman (2003), Comparison of transient storage in vegetated and unvegetated reaches of a small agricultural stream in Sweden: seasonal variation and anthropogenic manipulation: Adv. Water Res., 26, 951-965.

Sardin, M., D. Schweich, F.J. Keij, and M.T. van Genuchten (1991), Modeling the nonequilibrium transport of linearly interacting solutes in porous media: A review, Water Resour. Res., 27(9), 2287-2307. 
Squillace, P.J., E.M. Thurman, and E.T. Furlong (1993), Groundwater as a nonpoint source of atrazine and deethylatrazine in a river during base flow conditions, Water Resour. Res., 29(6), 1719-1729.

Stofleth, J. M., F.D. Shields, Jr., and G.A. Fox (2008), Hyporheic and total transient storage in small, sand-bed streams, Hydrol. Process., 22, 1885-1894.

Taylor, G.I. (1954), The dispersion of matter in turbulent flow through a pipe, Proceedings of the Royal Society of London, Series A, 233, 446-468.

Thackston, E.L. and K.B. Schnelle Jr. (1970), Predicting the effects of dead zones on stream mixing, J. Sanitary Eng. Div., Proceedings of the American Society of Civil Engineers, ASCE, 319-331.

Thomas, S.A., H.M. Valett, P.J. Mulholland, C.S. Fellows, J.R. Webster, C.N. Dahm, and C.G. Peterson (2001), Nitrogen retention in headwater streams: the influence of groundwatersurface water exchange: Optimizing Nitrogen Management in Food and Energy Production and Environmental Protection, paper presented at Proceedings of the 2nd International Nitrogen Conference on Science and Policy, 1(S2), 623-631.

Topcon Corporation (2008), Topcon GTS-230W-Series Electronic Total Station Instruction Manual, Topcon Positioning Systems, Inc., Pleasanton, California.

Uijttewaal, W. S. J., D. Lehmann, and A.V. Mazijk (2001), Exchange processes between a river and its groyne fields: model experiments, J. Hydraul. Eng., 127(11), 928-936.

Uijttewaal, W. S. J. (2005), Effects of groyne layout on the flow in groyne fields: Laboratory experiments, J. Hydraul. Eng., 131(9), 782-791.

Valentine, E. M., and I.R. Wood (1977), Longitudinal dispersion with dead zones, J. Hydraul. Eng., 103(9), 975-990.

Valett, H. M., M. J. A., C.N. Dahm, and M.E. Campana (1996), Parent lithology, surfacegroundwater exchange, and nitrate retention in headwater streams, Limnol. Oceanogr., 41, 333-345.

Villermaux, J. (1974), Deformation of chromatographic peaks under the influence of mass transfer phenomena, J. Chromatographic Sci, 12, 822-831.

Villermaux, J. (1981), Theory of linear chromatography, in Percolation Processes, Theory and Applications, edited by A. E. Rodrigues and D. Tondeur, pp. 83-141, Sijthoff and Noordhoff, Rockville, Massachusetts.

Wallast, I., W. Uijttewaal, and A. van Mazijk (1999), Exchange processes between groyne field and main stream, P. $28^{\text {th }}$ IAHR Congress, Graz.

Weitbrecht, V., and G.H. Jirka (2001), Flow patterns and exchange processes in dead zones of rivers: P. $29^{\text {th }}$ IAHR Congress, Beijing, China.

Weitbrecht, V. (2004), Influence of dead-water zones on the dispersive mass transport in rivers, Ph.D. Dissertation, University of Karlsruhe, Karlsruhe, Germany.

Weitbrecht, V., S.A. Socolofsky, and G.H. Jirka (2008), Experiments on mass exchange between groin fields and main stream in rivers, J. Hydraul. Eng., 134(2), 173-183.

Wilcox, D.C. (2006), Turbulence Modeling for CFD, 3rd ed., DCW Industries.

Wörman, A., A.I. Packman, H. Johansson and K. Jonsson (2002), Effect of flow-induced exchange in hyporheic zones on longitudinal transport of solutes in streams and rivers, Water Resour. Res., 38(1), 1001, 1010.1029/2001WR000769.

Wörman, A., A.I. Packman, L. Marklund, J.W. Harvey and S.H. Stone (2007), Fractal topography and subsurface water flows from fluvial bedforms to the continental shield, Geophys. Res. Lett., 34, L07402, doi:07410.01029/02007GL029426. 
Figure 1. Conceptualization of a natural lateral surface transient storage zone. (a) Schematic diagram showing plan and cross-sectional views of a straight channel reach with a lateral STS zone used to illustrate physically-based properties of the main channel and STS. (b) Plan view of velocity field associated with a typical lateral STS from Site 1P along Oak Creek in the Oregon State University McDonald-Dunn Research Forest near Corvallis, Oregon. 3-D depth-averaged velocity field obtained from a Reynolds-Averaged Navier-Stokes computational fluid dynamics model.

Figure 2. Schematic diagram showing plan view of an open channel reach with a rectangular STS used to illustrate physically-based properties of the main channel and STS. Note that all variables correspond to STS box model.

Figure 3. Field measurements of a lateral STS along Oak Creek, Oregon (Site 2P). (a) rhodamine WT dye used to delineate location of shear layer and recirculation region in STS. (b) $\mathrm{NaCl}$ injection experimental set-up using pump-driven distribution system. (c) Schematic of $\mathrm{NaCl}$ injection experiment and location of primary and secondary gyres relative to electrical conductivity (EC) sensors for (b).

Figure 4. Comparison of residence times for a one-exponential and two-exponential residence time distribution (RTD). For a one-exponential RTD, the STS mean residence time, $\tau_{\text {STS }}$, computed as the area beneath the normalized concentration curve for $0 \leq t<T_{2}=\infty, I_{0}^{T_{2}}$, is equal to the inverse slope of the exponential decay function, $\tau_{1}$, and the Langmuir timescale, $\tau_{L}$. For a two-exponential RTD, there exists an early time for initiation of exponential decay, $T_{1}$, and a late time of exponential decay, $T_{2}$, that occurs at the abrupt change in exponential slope. $\tau_{L}$ is approximately equivalent to the area beneath the normalized concentration curve for $T_{1}<t \leq T_{2}$, $I_{T_{1}}^{T_{2}} \cdot \tau_{S T S}$ is equal to the inverse slope of the first exponential decay function, $\tau_{1}$, and is approximately equivalent to the area beneath the normalized concentration curve for $0 \leq t \leq T_{2}$, $I_{0}^{T_{2}}$. The measured apparent STS mean residence time, $\tau_{a p}$, is approximately equivalent to the inverse slope of the second exponential decay function, $\tau_{2}$, and is equal to the area beneath the normalized concentration curve for $0 \leq t<\infty, I_{0}^{\infty}$. Note that, in some cases, the RTD will have an initial plateau concentration because of the time lag between turning off the pump and the initial release of tracer from the STS into the main channel, as shown by the two-exponential RTD. The initial plateau concentration results in a differentiation between $t=0$ and $t=T_{1}$ when (a) approximating $\tau_{L}$ from $I_{T_{1}}^{T_{2}}$ if $T_{1} \neq 0$ for a two-exponential RTD; and (b) approximating a best-fit line for the first exponential decay function for both the one- and two-exponential RTD, where the best-fit line is fitted to data for $T_{1}<t \leq T_{2}$. Data in the two-exponential RTD are from the STS at site 1 on Oak Creek shown in Figure $1 \mathrm{~b}$.

Figure 5. (a) Concentration BTCs for 3 different constant-rate $\mathrm{NaCl}$ injection experiments and all electrical conductivity (EC) probes at Site 2P (Oak Creek, Oregon) shown in Figure 3. Oscillations in steady-state concentrations due to unsteady nature of gyres in vicinity of probes. Notice that the BTC for probe 5 lags behind the other probes because of its location in a 
secondary gyre (see Figure 3). (b) $\tau_{1}$ computed for each EC probe, which each have a oneexponential RTD. Error bars represent percent bias error. Notice that all probes located in primary gyre (all but EC 5) have the same mean residence time, but the probe in the secondary gyre has a significantly larger mean residence time. (c) Mean normalized concentration BTCs for three $\mathrm{NaCl}$ injection experiments that show the range of variability between experiments, where more variability exists at later times. The late-time variability is attributed to the relatively short time duration between experiments ( $20 \mathrm{~min})$, which results in more $\mathrm{NaCl}$ in poorly-mixed regions (secondary gyres) initially that exchanges with the primary gyre. Note that the size of markers for the field data represent one standard error of the residence timescale $( \pm 2 \%)$.

Figure 6. Comparison of the area beneath the normalized concentration curve for $T_{1}<t \leq T_{2}$, denoted $I_{T_{1}}^{T_{2}}$, to the Langmuir timescale, $\tau_{L}$, for field data with one-exponential and twoexponential RTDs. Note that the size of markers for the field data represent one standard error of the residence timescale ( $\pm 2 \%$ for $I_{T_{1}}^{T_{2}}$ and $\pm 6 \%$ for the Langmuir timescale). These errors are associated with uncertainties in instrumentation and measurement where, for the natural lateral STS, the electrical conductivity sensors yield a range of error of \pm 2 percent.

Figure 7. Comparison of the area beneath the normalized concentration curve for $0 \leq t \leq T_{2}$, denoted $I_{0}^{T_{2}}$ where $T_{2}=\infty$ for a one-exponential RTD, to the inverse slope of the first exponential decay function, $\tau_{1}$, for field data with one-exponential and two-exponential RTDs. Both $I_{0}^{T_{2}}$ and $\tau_{1}$ are measures of the STS mean residence time, $\tau_{\text {STS }}$. Note that the size of markers for the field data represent one standard error of the residence timescale $( \pm 2 \%$ for both timescales). These errors are associated with uncertainties in instrumentation and measurement where, for the natural lateral STS, the electrical conductivity sensors yield a range of error of \pm 2 percent.

Figure 8. Comparison of the area beneath the normalized concentration curve for $0 \leq t<\infty$, denoted $I_{0}^{\infty}$, to the inverse slope of the second exponential decay function, $\tau_{2}$, for field data with two-exponential RTDs. Both $I_{0}^{\infty}$ and $\tau_{2}$ are measures of the measured apparent STS mean residence time, $\tau_{a p}$. Note that the size of markers for the field data represent one standard error of the residence timescale $( \pm 2 \%$ for both timescales). These errors are associated with uncertainties in instrumentation and measurement where, for the natural lateral STS, the electrical conductivity sensors yield a range of error of \pm 2 percent.

Figure 9. Comparison of ratio of Langmuir timescale, $\tau_{L}$, to the main channel convective timescale (length at main channel-STS interface to mean main channel velocity, $L / U$ ) versus the STS aspect ratio (STS width to length at main channel-STS interface, $W / L$ ). Note that the size of markers for the field data represent the range of error, which is one standard error $( \pm 6 \%$ for the scaled Langmuir timescale and $\pm 1 \%$ for the $W / L$ aspect ratio). These errors are associated with 
uncertainties in instrumentation and the velocity flowmeter, which yields a range of error of \pm 2 percent.

Figure 10. Comparison of the measured apparent mean residence time of STS (estimated as the area beneath the normalized concentration curve for $0 \leq t<\infty$, denoted $I_{0}^{\infty}$ ) to physically-based stream properties (based on Uijttewaal et al. [2001] mean residence time from (9)). Note that the size of markers for the field data represent the range of error, which is one standard error $( \pm 2 \%$ for $I_{0}^{\infty}$ and $\pm 5 \%$ for the Uijttewaal et al. [2001] timescale). These errors are associated with uncertainties in instrumentation and velocity flowmeter, which yield a range of error of \pm 2 percent. The estimated entrainment coefficients from the trend lines are $0.016 \pm 0.007$ for all data, and $0.019 \pm 0.006$ for the field data.

Figure 11. Comparison of the STS mean residence time (estimated as the inverse slope of the first exponential decay function, $\tau_{1}$ ) to physically-based stream properties (based on Uijttewaal et al. [2001] mean residence time from (9)). Note that the size of markers represent the range of error, which is one standard error $\left( \pm 2 \%\right.$ for $\tau_{1}$ and $\pm 5 \%$ for the Uijttewaal et al. [2001] timescale). These errors are associated with uncertainties in instrumentation and velocity flowmeter, which yield a range of error of \pm 2 percent. Note that the estimated entrainment coefficient from the field data $(k=0.031)$ is greater than that for the apparent measured mean residence time by a factor of approximately 2 . 
Table 1. Summary of field measurements for lateral STS sites.

\begin{tabular}{|c|c|c|c|c|c|c|c|c|c|c|}
\hline & Location $^{1}$ & $\begin{array}{c}\mathrm{W} \\
(\mathrm{m})\end{array}$ & $\begin{array}{c}\mathrm{L} \\
(\mathrm{m})\end{array}$ & $\begin{array}{c}\mathrm{W} / \mathrm{L} \\
{[-]}\end{array}$ & $\begin{array}{l}\mathrm{d}_{\text {STS }} \\
(\mathrm{m})\end{array}$ & $\begin{array}{c}\mathrm{d}_{\mathrm{E}} \\
(\mathrm{m})\end{array}$ & $\begin{array}{c}\mathrm{U} \\
(\mathrm{m} / \mathrm{s})\end{array}$ & $\begin{array}{l}\mathrm{T}_{\mathrm{L}} \\
\text { (s) }\end{array}$ & $\mathrm{RTD}^{2}$ & $R e^{3}$ \\
\hline Site 1P & OC & 0.54 & 1.69 & 0.32 & 0.12 & 0.14 & 0.35 & 27 & 2 & $3.2 \times 10^{4}$ \\
\hline Site $2 \mathrm{P}$ & OC & 0.64 & 1.47 & 0.43 & 0.11 & 0.18 & 0.19 & 97 & 2 & $9.0 \times 10^{3}$ \\
\hline Site 3P & OC & 0.49 & 0.90 & 0.54 & 0.05 & 0.09 & 0.33 & 45 & 1 & $2.3 \times 10^{4}$ \\
\hline Site 4P & OC & 1.07 & 1.91 & 0.56 & 0.10 & 0.15 & 0.20 & 121 & 2 & $1.5 \times 10^{4}$ \\
\hline Site 1S & OC & 0.55 & 1.95 & 0.28 & 0.07 & 0.12 & 0.20 & 129 & 1 & $9.9 \times 10^{3}$ \\
\hline Site 3S & OC & 1.90 & 3.50 & 0.54 & 0.21 & 0.26 & 0.12 & 584 & 2 & $8.4 \times 10^{3}$ \\
\hline Site $4 S$ & OC & 0.50 & 1.45 & 0.34 & 0.07 & 0.12 & 0.08 & 100 & 2 & $5.2 \times 10^{3}$ \\
\hline Site 5P & SC & 0.93 & 1.25 & 0.74 & 0.17 & 0.09 & 0.53 & 65.4 & 2 & $2.6 \times 10^{4}$ \\
\hline Site $6 S$ & SC & 0.60 & 1.30 & 0.46 & 0.05 & 0.08 & 0.13 & 112 & 2 & $7.5 \times 10^{3}$ \\
\hline Site 7S & SC & 0.60 & 2.05 & 0.29 & 0.12 & 0.26 & 0.24 & 50 & 1 & $3.1 \times 10^{4}$ \\
\hline Site $8 \mathrm{~S}$ & SC & 0.60 & 2.05 & 0.29 & 0.08 & 0.16 & 0.30 & 49 & 1 & $3.0 \times 10^{4}$ \\
\hline Site 9S & SC & 0.55 & 2.25 & 0.24 & 0.14 & 0.27 & 0.17 & 75 & 1 & $1.5 \times 10^{4}$ \\
\hline Site $10 \mathrm{~S}$ & SC & 0.60 & 3.05 & 0.20 & 0.06 & 0.15 & 0.24 & 77 & 1 & $1.5 \times 10^{4}$ \\
\hline Site $15 S$ & SC & 1.80 & 5.30 & 0.34 & 0.09 & 0.18 & 0.22 & 263 & 1 & $1.4 \times 10^{4}$ \\
\hline Site $16 \mathrm{~S}$ & SC & 1.45 & 4.35 & 0.33 & 0.08 & 0.17 & 0.15 & 69 & 1 & $1.2 \times 10^{4}$ \\
\hline Site $17 \mathrm{~S}$ & SC & 1.95 & 3.30 & 0.59 & 0.18 & 0.23 & 0.29 & 207 & 2 & $1.6 \times 10^{4}$ \\
\hline Site $11 S$ & JD & 0.90 & 3.15 & 0.29 & 0.17 & 0.43 & 0.74 & 37 & 1 & $1.8 \times 10^{5}$ \\
\hline Site $12 \mathrm{~S}$ & $\mathrm{JD}$ & 1.90 & 3.85 & 0.49 & 0.26 & 0.36 & 0.68 & 82 & 1 & $1.2 \times 10^{5}$ \\
\hline Site 13S & JD & 1.00 & 3.10 & 0.32 & 0.35 & 0.48 & 0.53 & 55 & 1 & $1.2 \times 10^{5}$ \\
\hline Site 19S & LC & 1.45 & 2.40 & 0.60 & 0.17 & 0.42 & 0.31 & 174 & 1 & $2.9 \times 10^{4}$ \\
\hline Site 20S & LC & 1.50 & 3.40 & 0.44 & 0.28 & 0.37 & 0.23 & 138 & 1 & $2.7 \times 10^{4}$ \\
\hline Site 21S & LC & 1.15 & 1.90 & 0.61 & 0.16 & 0.37 & 0.43 & 138 & 1 & $5.0 \times 10^{4}$ \\
\hline
\end{tabular}

${ }^{\mathrm{T}}$ Field site location:

OC = Oak Creek, Oregon State University McDonald-Dunn Research Forest near Corvallis, OR;

SC = Soap Creek, Oregon State University McDonald-Dunn Research Forest near Corvallis, OR;

JD = Middle Fork of John Day River, eastern OR;

LC = Lookout Creek, H.J. Andrews Experimental Forest, western Cascades, OR

${ }^{2}$ RTD column defines site as having either a one- or two-exponential RTD.

${ }^{3} R e$ is computed using the main channel wetted perimeter. 
Table 2. Laboratory flume studies and estimated $k$ values.

\begin{tabular}{l|l|l} 
Laboratory Study & Description of Flume Set-Up & \multicolumn{1}{l}{$k^{*}$} \\
\hline This study & Natural lateral STS & $0.031 \pm 0.009(n=20)$ \\
Valentine and Wood [1977] & Vertically-submerged STS & $0.02 \pm 0.01(n=67)$ \\
Seo and Maxwell [1992] & Pools between gravelly riffles & $0.037 \pm 0.032(n=12)$ \\
Wallast et al. [1999] & Series of lateral groynes & $0.02 \pm 0.01(n=4)$ \\
Uijttewaal et al. [2001] & Series of lateral groynes & $0.026 \pm 0.040(n=7)$ \\
Kurzke et al. [2002] & Series of lateral groynes & $0.024 \pm 0.014(n=15)$ \\
Weitbrecht and Jirka [2001] & Series of lateral groynes & $0.029(n=1)$ \\
McCoy et al. [2006] & Single lateral groyne & $0.061 / 0.032(n=1)$ \\
Hinterberger et al. [2007] & Series of lateral groynes & $0.027(n=1)$ \\
Chang et al. [2007] & Vertically-submerged STS & $0.013(n=1)$ \\
Weitbrecht et al. [2008] & Series of lateral groynes & $0.024 \pm 0.014(n=18)$ \\
Constantinescu et al. [2009] & Series of lateral groynes & $0.018 / 0.014(n=1)$ \\
\hline
\end{tabular}

${ }^{*} k$ value range is mean \pm 2 standard deviations

${ }^{* *} \mathrm{RTD}$ is a two-exponential distribution (initial phase $k$ / final phase $k$ ) 


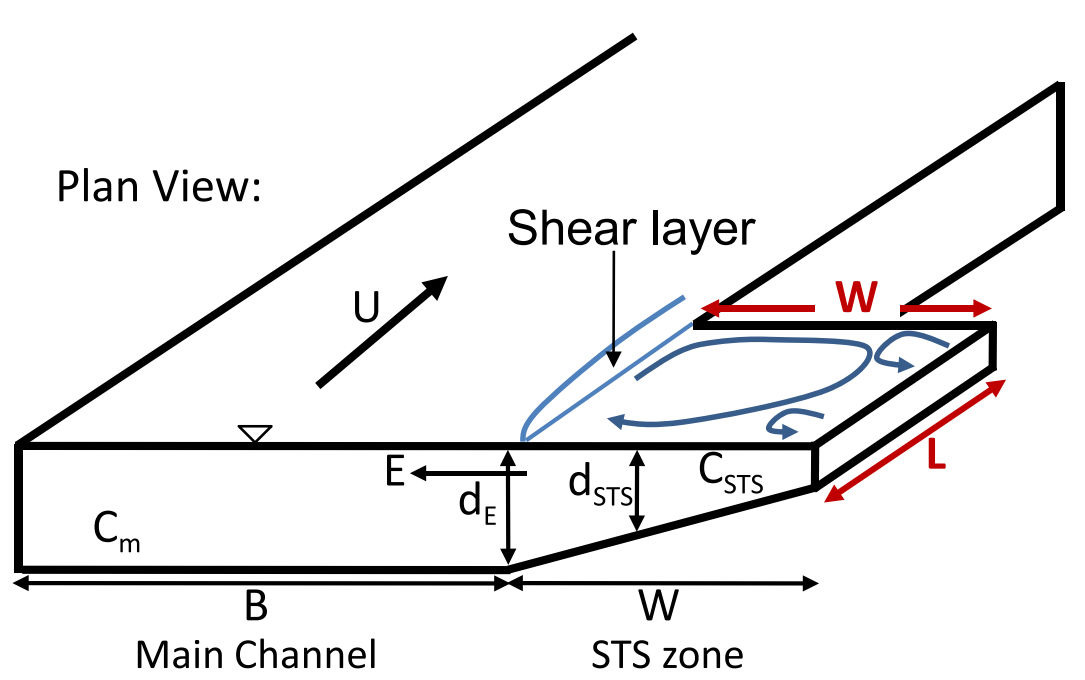

b)

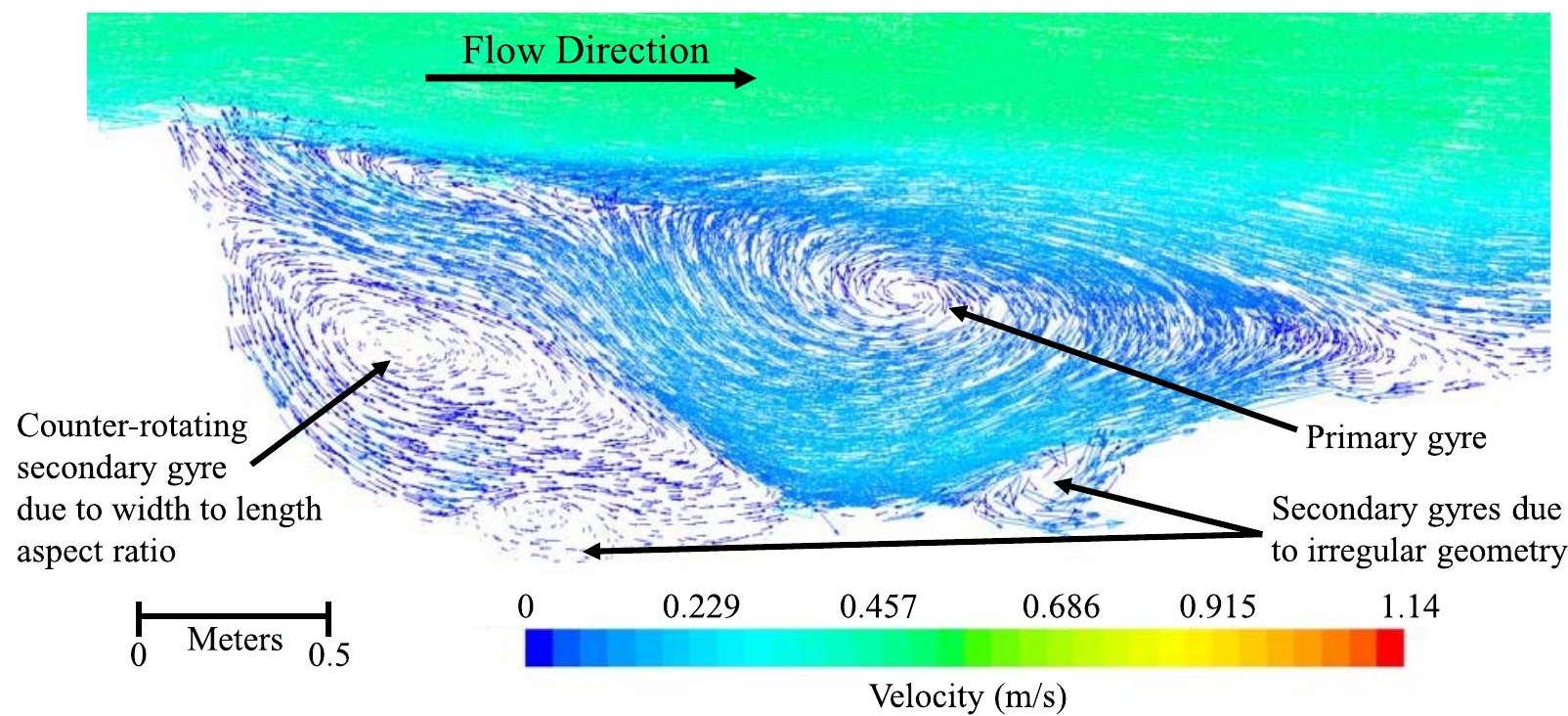


Plan View:

Shear layer

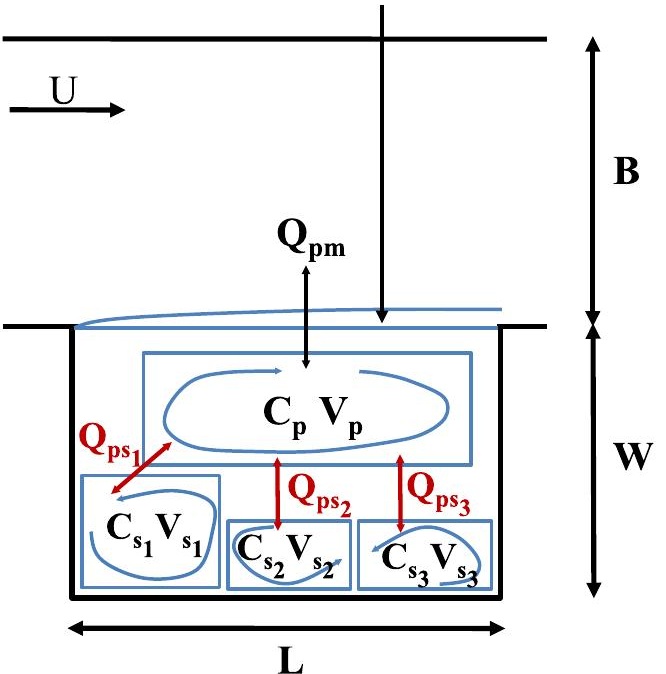




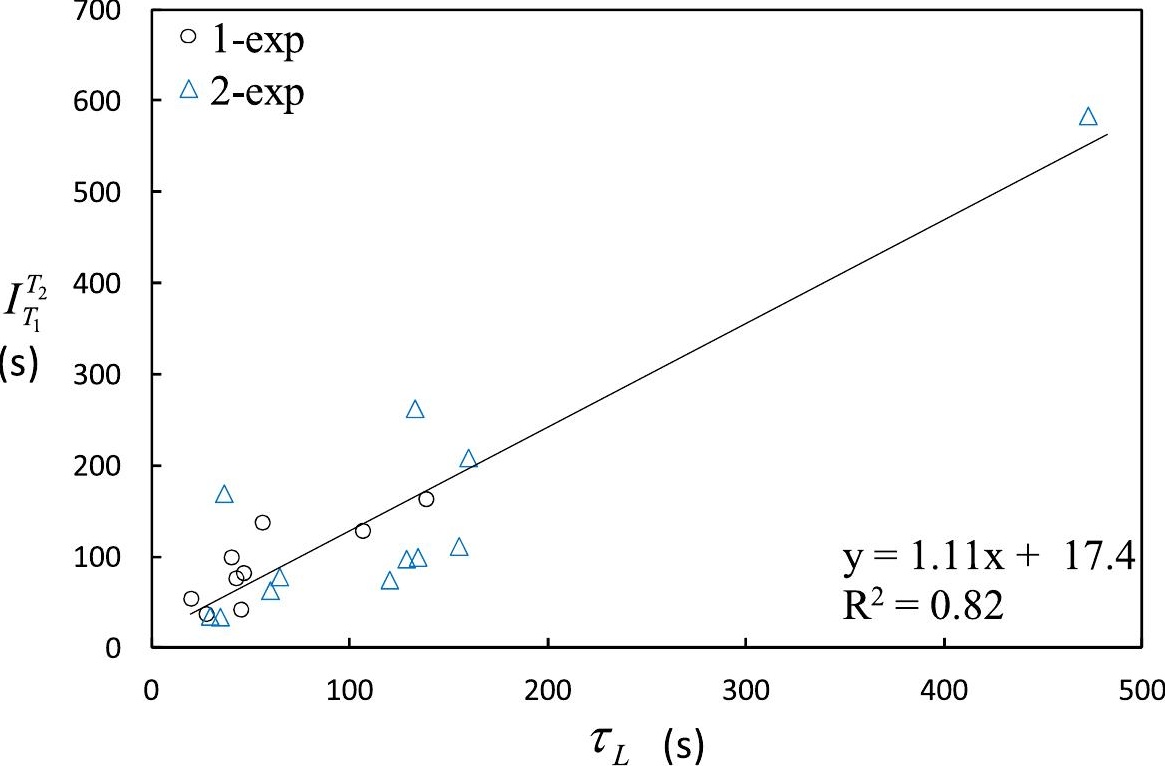




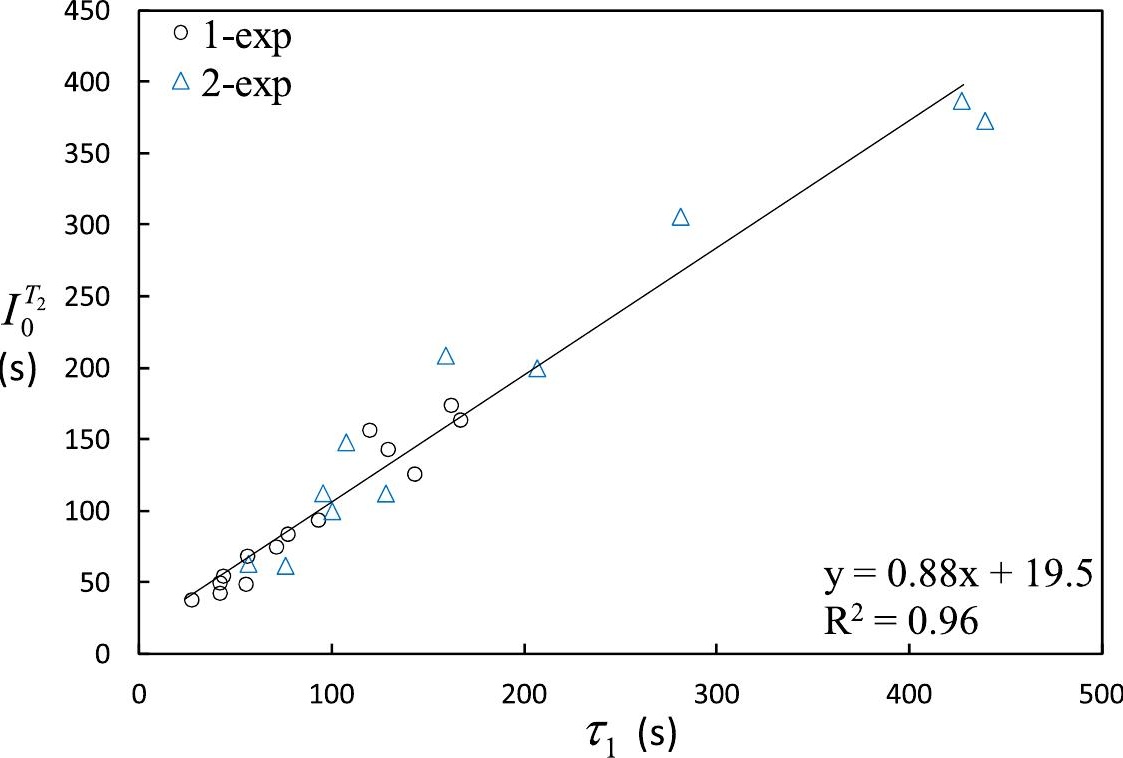


- Field Data

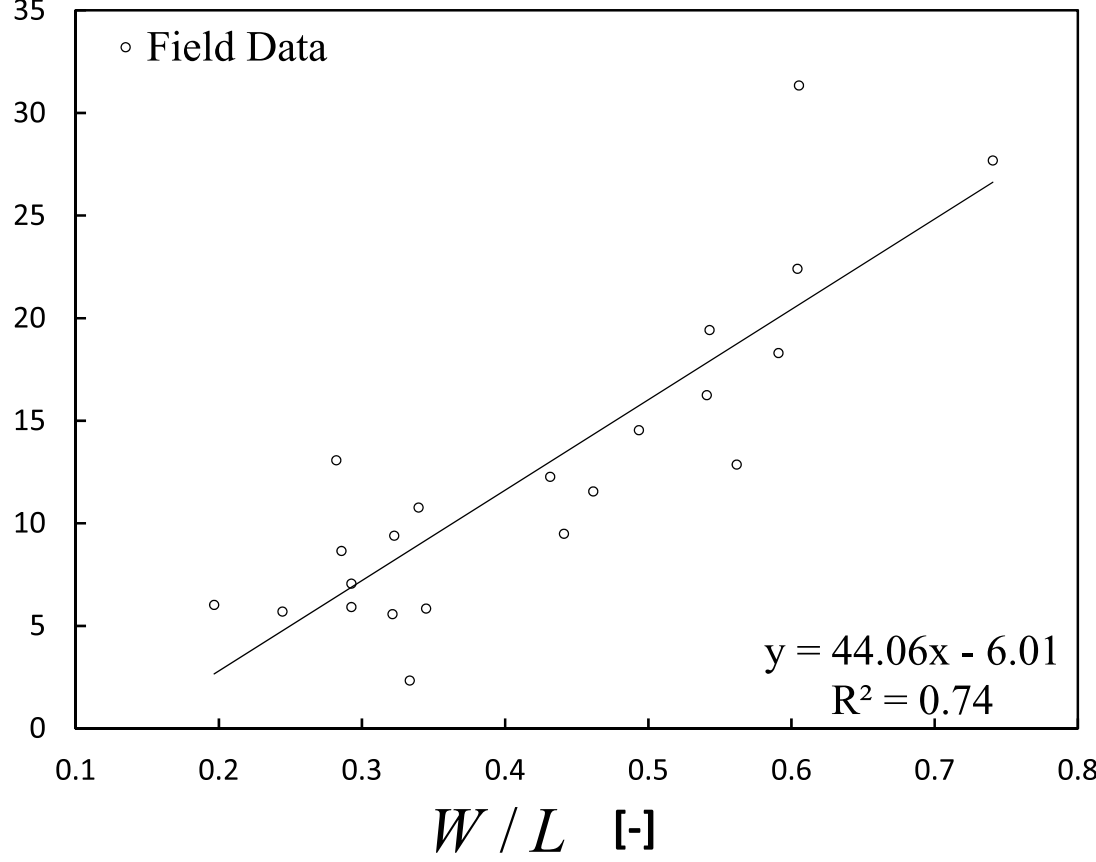




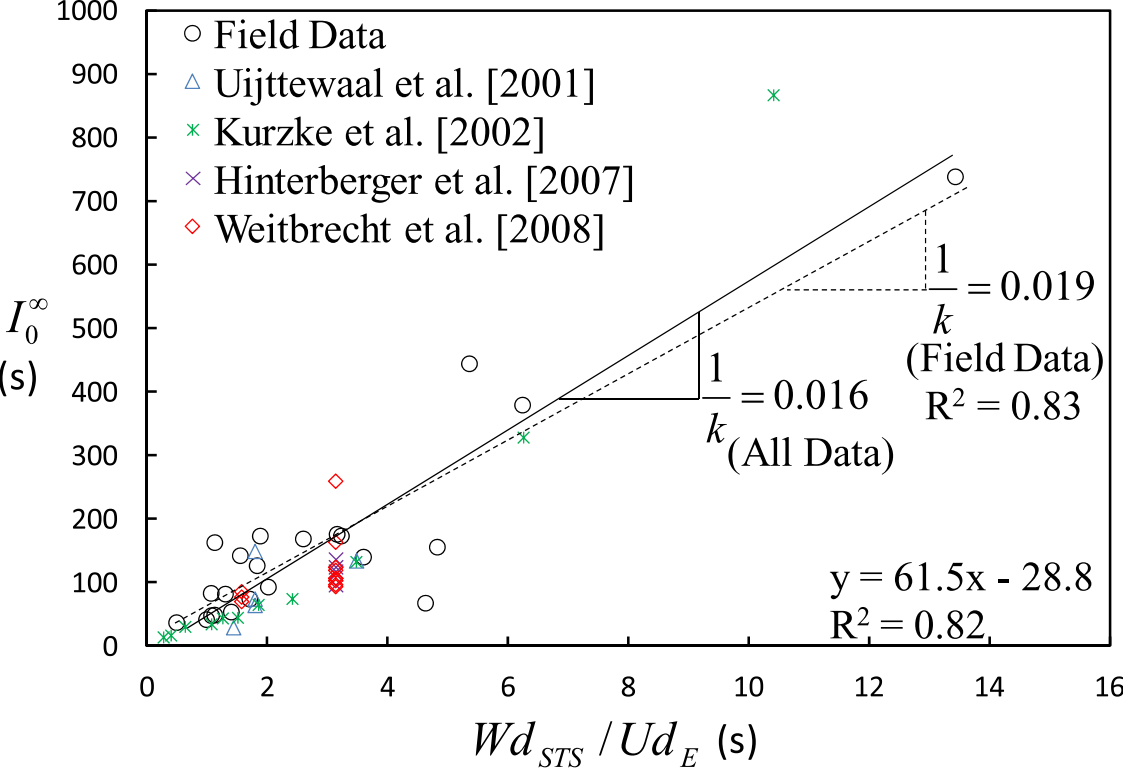




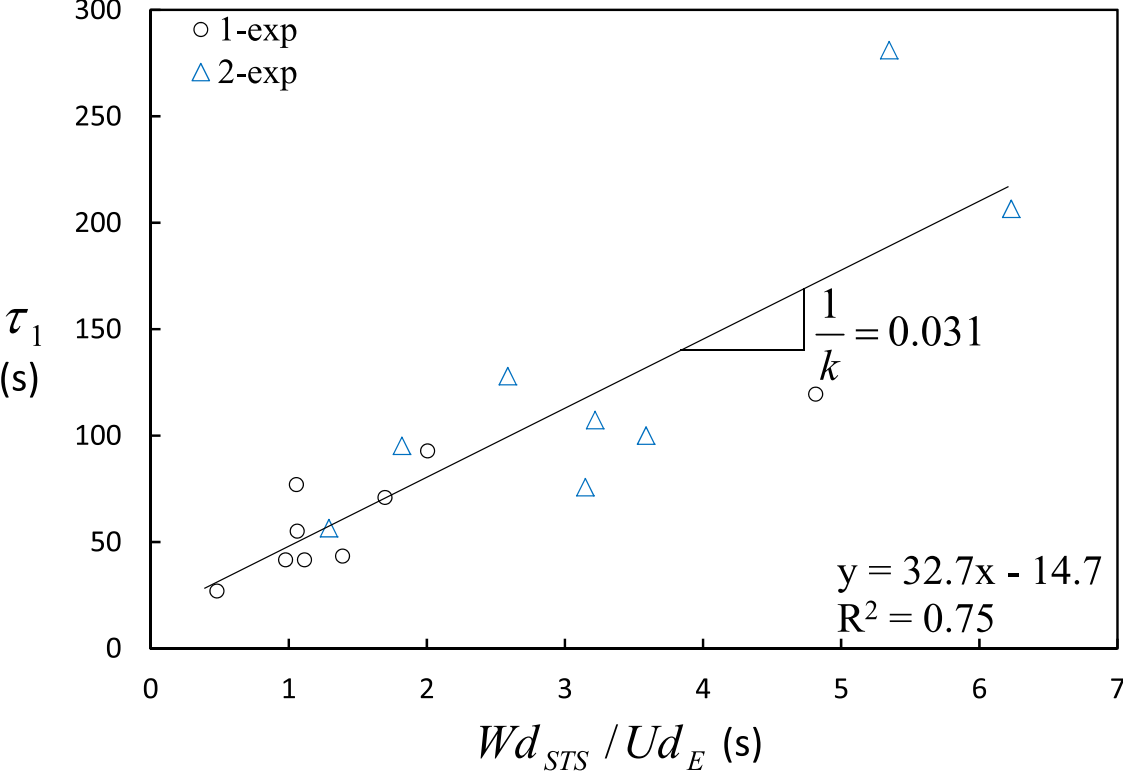

